\title{
New species of Aprionus (Diptera, Cecidomyiidae, Micromyinae) from Sweden and other parts of the Palearctic region
}

\author{
Mathias JASCHHOF ${ }^{1, *}$ \& Catrin JASCHHOF ${ }^{2}$ \\ ${ }^{1,2}$ Station Linné, Ölands Skogsby 161, SE-38693 Färjestaden, Sweden. \\ *Corresponding author: mjaschhof@yahoo.de \\ 2 Email: cjaschhof@yahoo.de \\ ${ }^{1}$ urn:1sid:zoobank.org:author:8B4B11B4-7C33-41AC-A042-AA9903CDC4B1 \\ ${ }^{2}$ urn:1sid:zoobank.org:author:BE4CA083-88F6-4037-826D-605FFF5078F7
}

\begin{abstract}
Aprionus Kieffer, 1894 is one of the most species-rich genera of the fungivorous subfamily Micromyinae (family Cecidomyiidae, gall midges). Eighteen new species of this genus are described here from different parts of the Palearctic region based on morphological characters of male adults: Aprionus balduri sp. nov. (Norway, Sweden), A. bestlae sp. nov. (Sweden, Czech Republic), A. borri sp. nov. (Sweden), A. fontanus sp. nov. (Germany), A. friggae sp. nov. (Sweden), A. fujisanensis sp. nov. (Japan), A. hugini sp. nov. (Sweden, Germany), A. magnii sp. nov. (Sweden), A. montivagus sp. nov. (Germany, Russia), A. munini sp. nov. (Sweden, Germany, Hungary), A. odini sp. nov. (Sweden), A. ogawaensis sp. nov. (Japan), A. sifae sp. nov. (Sweden), A. sleipniri sp. nov. (Sweden), A. surtri sp. nov. (Sweden), A. thori sp. nov. (Sweden), A. tyri sp. nov. (Sweden), and A. ymiri sp. nov. (Sweden, Finland). These species are classified with the angulatus, halteratus and smirnovi groups, or remain unclassified within the genus Aprionus. The styloideus subgroup of the halteratus group is established for seven species (four described here as new) with generally similar male genitalic morphology. Aprionus paludosus Jaschhof \& Mamaev, 1997 is revived from synonymy with A. styloideus Mamaev \& Berest, 1990, and both species are redescribed.
\end{abstract}

Keywords. Gall midges, fungivores, morphology, male genitalia.

Jaschhof M. \& Jaschhof C. 2017. New species of Aprionus (Diptera, Cecidomyiidae, Micromyinae) from Sweden and other parts of the Palearctic region. European Journal of Taxonomy 378: 1-38.

https://doi.org/10.5852/ejt.2017.378

\section{Introduction}

Fungivorous gall midges of the genus Aprionus Kieffer, 1894 are among the most common Micromyinae in Palearctic woodlands. Of 113 species described in the past, only six are extra-Palearctic (Gagné \& Jaschhof 2014; Jaschhof \& Jaschhof 2015; Jaschhof 2015, 2016). Since vast stretches of the Palearctic region are unexplored for Aprionus (as well as for other Micromyinae), we assume there remain many, presumably hundreds of unnamed species to be collected and scientifically described. Taxonomic inventory continues to uncover new species even in areas where Aprionus has been studied more 
thoroughly in the past. In Sweden, the origin of most of the newly described species in recent years, the number of species of Aprionus stood previously at 80 (Jaschhof 2015; Jaschhof \& Jaschhof 2015, 2016) and is increased here by another 15 .

In this paper, 18 new species of Aprionus are described, named and related to the subgeneric classification developed in our previous publications (Jaschhof 1998; Jaschhof \& Jaschhof 2009). Three of the species groups maintained within Aprionus are addressed here more closely: the angulatus, halteratus and smirnovi groups (Jaschhof \& Jaschhof 2009). As will become apparent, the interrelationships of Aprionus become clearer with more new species being morphologically described and analysed, a circumstance proving the explanatory power of comparative morphology, even in large and diverse genera.

\section{Material and methods}

Most of the specimens (male adults) for this study were collected using Malaise traps, a few others with various other traps, sweep net and aspirator. The study material is in large part an outcome of two projects: the Gall Midge Project, an ongoing venture to inventory the Cecidomyiidae of Sweden (http://www.stationlinne.se/sv/forskning/the-gall-midge-project, accessed 26 Nov. 2016) and the Swedish Malaise Trap Project (SMTP; http:/www.stationlinne.se/sv/forskning/the-swedish-malaisetrap-project-smtp, accessed 26 Nov. 2016). Other specimens studied here are from the Jaschhof collection of Cecidomyiidae in the Senckenberg Deutsches Entomologisches Institut, Müncheberg, Germany (DEI), or were provided to us over the years by various fellow entomologists (see Acknowledgements).

Specimens, both types and other vouchers, were mounted on microscopic slides in Canada balsam and studied by transmitted-light microscope, following the procedures described in detail by Jaschhof \& Jaschhof (2009). Final depository of specimens was made with the following collections (acronyms in parentheses): Naturhistoriska Riksmuseet Stockholm, Sweden (NHRS); DEI; Entomological Collection of Kyushu University, Fukuoka, Japan (KUEC); Museum Niederösterreich, St. Pölten, Austria (MNSP); and the personal collection of Tomáš Sikora, Ostrava, Czech Republic (TSPC).

The morphological terminology used here is in accordance with that generally applied in Micromyinae (Jaschhof \& Jaschhof 2009). Morphological terms specific to Aprionus are explained here in Figs 2 and 18 , with the following abbreviations used:

gcx ext $=$ medial extensions of gonocoxal apodemes

sub pl = subanal plate

teg fing $=$ finger-like process of tegmen or tegminal finger

The male gonocoxites of Aprionus (and of other Micromyinae) are largely merged into a single structure and thus described as a unit. Body size is given including the genitalia, which in Aprionus males are large. Arrows $(\downarrow)$ are used to highlight important diagnostic characters in both the wording and illustrations of a taxonomic description. To avoid reiteration, a section 'Other characters' is employed to refer to characters not mentioned in the preceding diagnosis and differential diagnosis of a treatment. Numerous new species from Sweden are named after figures from Old Norse mythology, a circumstance not further mentioned in the particular etymology sections. Taxa are treated in alphabetical order.

Other abbreviations used in the text, but not for holotype data, are:

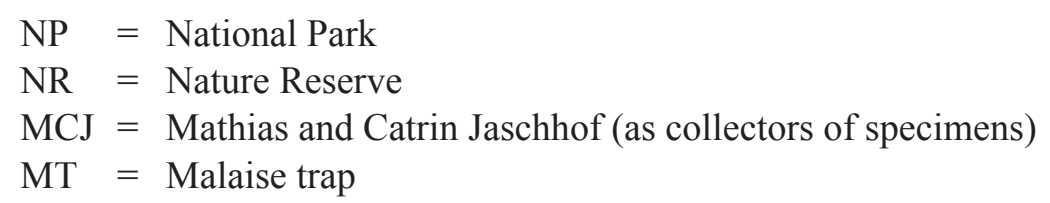




\title{
Results
}

\author{
Class Insecta Linnaeus, 1758 \\ Order Diptera Linnaeus, 1804 \\ Suborder Bibionomorpha Hennig, 1954 \\ Family Cecidomyiidae Newman, 1834 \\ Subfamily Micromyinae Rondani, 1856
}

Genus Aprionus Kieffer, 1894

The genus has recently been revised (Jaschhof 1998) and updated (Jaschhof 2015, 2016; Jaschhof \& Jaschhof 2009, 2015, 2017), a circumstance that greatly facilitates identifying and classifying unnamed species. Even so, to distinguish closely related Aprionus from each other using male morphology (which is the routine method, see Jaschhof \& Jaschhof 2009) continues to be challenging. As shown here using the example of Aprionus styloideus Mamaev \& Berest, 1990, previously accepted names may denote species complexes rather than single species, with this kind of hidden biodiversity usually discovered when extensive new study material becomes available.

The genus Aprionus is defined by male genitalic characters, as follows (see Jaschhof \& Jaschhof 2009: 219). The gonocoxites are connected ventrobasally by an extremely short bridge, typically a thin, curvate, sclerotized bar; the tegmen of many species is provided with finger-like processes, a structure not known from other Micromyinae; and the hypoproct is present as a glabrous, usually partially sclerotized structure called subanal plate, which differs from the soft, microtrichose and often sparsely setose double-lobe forming the hypoproct in other Micromyinae.

\section{The angulatus group}

The angulatus group (eponym is Aprionus angulatus Mamaev, 1963) gathers species with the following male genitalic characters: the tegmen, which is made up of two lateral pillars with recurved apices, lacks finger-like processes; the gonocoxites are provided with a cone-shaped apodeme ventrobasally and subtriangular lobes ventroposteriorly; the ninth tergite usually has weakly sclerotized windows next to strongly sclerotized braces; and a subanal plate is usually absent (Jaschhof \& Jaschhof 2009: 223). The six previously known species were treated in detail by Jaschhof \& Jaschhof (2009). One species from Scandinavia and two species from Japan are newly described here. One of our Japanese species is exceptional in possessing a subanal plate.

Aprionus balduri sp. nov.

urn:lsid:zoobank.org:act:500C3CCF-E0E3-4201-98AB-605DE509F543

Fig. 1

\section{Diagnosis}

A typical representative of the angulatus group (Jaschhof \& Jaschhof 2009: 223), distinguished by the following male genitalic characters in combination. The ninth tergite (Fig. 1C) is lobed posterolaterally $(\downarrow)$, with a membranous area between the lobes. The ventroposterior gonocoxal lobes are very large ( $\downarrow$, Fig. 1A); the ventrobasal apodeme is strongly sclerotized ( $\downarrow$, Fig. 1A). The ventrobasal and dorsoapical portions of the gonostylus are the same size; the gonostylar apex is narrow ( $\downarrow$, Fig. 1B). The elongate tegmen has a large, rhombic central opening that lacks spinulae ( $\downarrow$, Fig. 1A).

\section{Etymology}

Baldur, a friendly god, is a son of Odin and his wife, Frigg. 


\section{Material examined}

Holotype

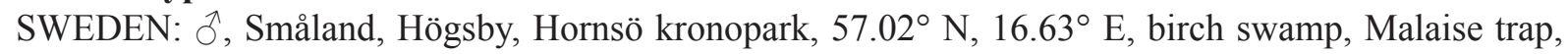
Swedish Malaise Trap Project (trap 18, collecting event 343), 20-30 Jul. 2004 (NHRS, no.CEC164).

\section{Paratype}

NORWAY: 1 ठૈ, Vestfold, Horten, Adalstjernet SE, MT, E. Rindal leg., 8 Jul.-12 Aug. 2003 (DEI, no. CEC165).

\section{Differential diagnosis}

Male genitalic structures of Aprionus balduri sp. nov. and A. angulatus (see Jaschhof \& Jaschhof 2009: figs $72 \mathrm{~A}, 75 \mathrm{~A}, 76 \mathrm{~A}$ ) are similar, but in the latter species the gonocoxal lobes are considerably smaller, the ninth tergite lacks a membranous area posteromedially, and the central tegminal opening is smaller and equipped with spinulae.

\section{Other characters}

Body size $1.1 \mathrm{~mm}$.

HEAD. Eye bridge 2-3 ommatidia long dorsally. A dense row of 10 postocular bristles. Neck of fourth flagellomere slightly shorter than node; translucent sensilla thick, simply hair-shaped. Palpus with 3 or 4 segments, even in one and the same specimen.

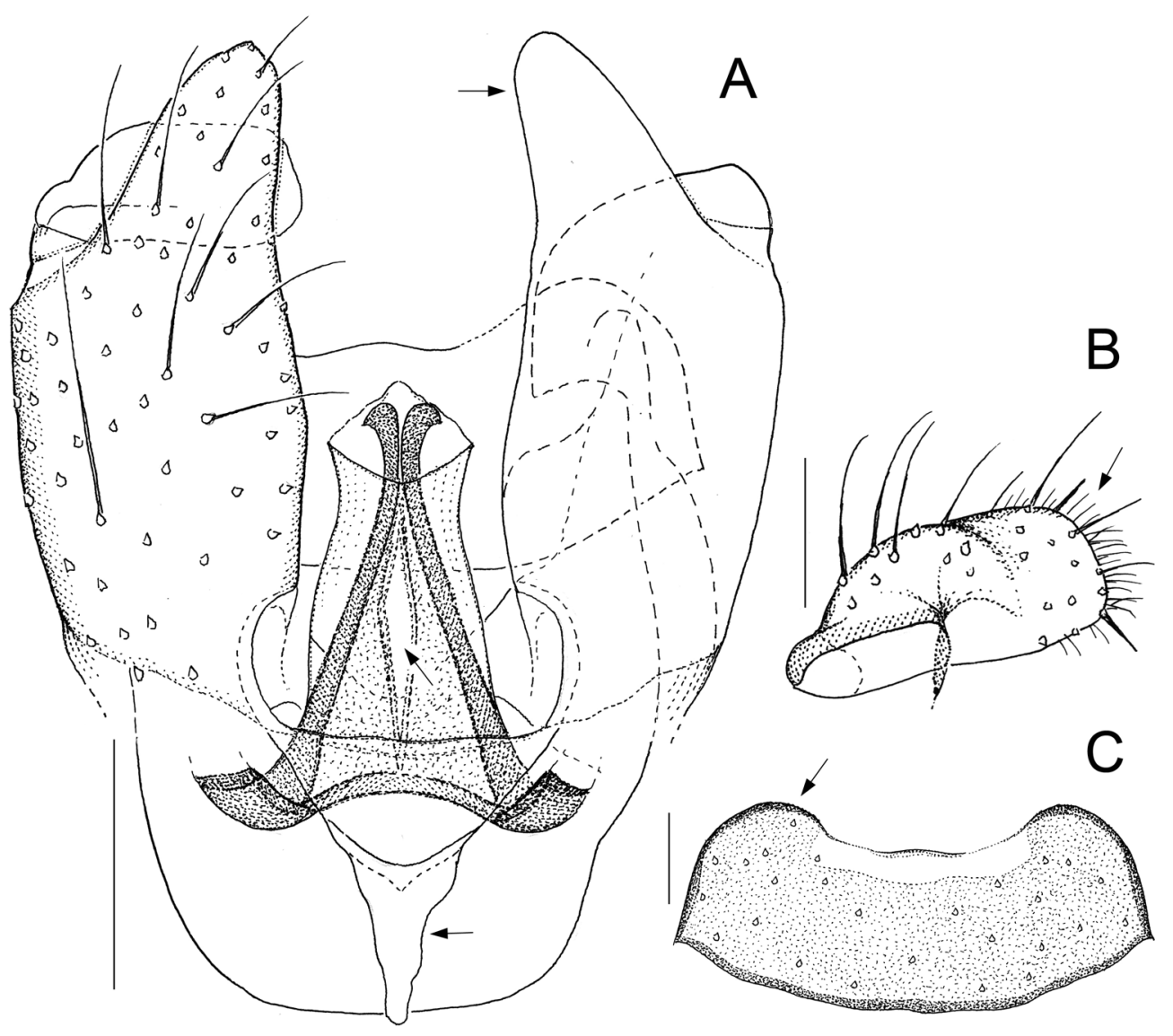

Fig. 1. Aprionus balduri sp. nov., holotype, ふึ. A. Genitalia, ventral. B. Gonostylus, ventral. C. Ninth tergite, dorsal. Scale lines: $0.05 \mathrm{~mm}$. Arrows indicate diagnostic characters. 
WING. ApicR 3 times as long as Rs. CuA straight, ends halfway to wing margin.

Legs. Claws sickle-shaped, 0-1 fine teeth. Empodia narrow, almost as long as claws.

TERminAlia. Ninth tergite short, anterior margin fully sclerotized (Fig. 1C). Medial extensions of gonocoxal apodemes sclerotized, interconnected medially. Gonostylus blunt-ended, $2+1$ short bristles among dense setulae and microtrichia apically (Fig. 1B). Lateral pillars of tegmen thin, in touch subapically, recurved apically (Fig. 1A).

\title{
Remark on the description
}

The antennae of the holotype have retained only the first flagellomeres, in the paratype one flagellum is missing and the other is collapsed, which explains why the fourth flagellomere cannot be illustrated here (as is routinely done with Aprionus).

\section{Distribution and phenology}

Norway (Vestfold), Sweden (Småland). This species is known from only two specimens, despite many years of collecting Micromyinae, including Aprionus, throughout Fennoscandia.

\author{
Aprionus fujisanensis sp. nov. \\ urn:1sid:zoobank.org:act:29B60EC7-5128-4999-B0A5-CBCA93ACD794
}

Fig. 2

\section{Diagnosis}

A key character of Aprionus fujisanensis sp. nov. is the tegmen whose unusually narrow lateral pillars ( $\downarrow$, Fig. 2A) form a perfect, inverted $\mathrm{V}$ basally, then run parallel to each other for quite a distance to end in membranous hooks. This conspicuous outline occurs in combination with small ventroposterior gonocoxal lobes ( $\downarrow$, Fig. 2A) and gonostyli with a narrow apex ( $\downarrow$, Fig. 2A).

\section{Etymology}

The species epithet refers to Fuji-san, the Japanese name for Mount Fuji, the type locality.

\section{Material examined}

\section{Holotype}

JAPAN: O, Honshu, Yamanashi, Oyama, east slope of Mount Fuji, $1900 \mathrm{~m}$ a.s.1., mature mixed coniferous forest, Malaise trap, M. and C. Jaschhof leg., 4-13 Jun. 1999 (KUEC, no. A7635).

\section{Paratypes}

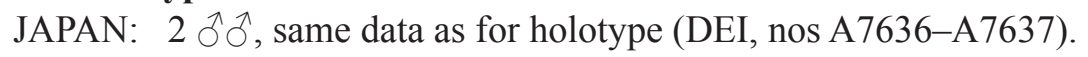

\section{Differential diagnosis}

Male genitalia in Aprionus fujisanensis sp. nov. and A. longitegminis Yukawa, 1967 are generally similar, but the latter has a slightly different tegmen and the ninth tergite is shorter (Jaschhof \& Jaschhof 2009: figs 74A, 76D). The strongly recurved CuA present in A. fujisanensis sp. nov. ( $\downarrow$, Fig. 2D) is shared with both A. longitegminis and A. brevitegminis Jaschhof, 2009, but not with other members of the angulatus group. Throughout this group, antennal translucent sensilla tend to branch, but this is most pronounced in A. fujisanensis sp. nov. ( $\downarrow$, Fig. 2B).

\section{Other characters}

Body size $1.4 \mathrm{~mm}$. 
HEAD. Eye bridge 2-3 ommatidia long dorsally. A sparse row of 6-7 postocular bristles. Neck of fourth flagellomere as long as node or slightly longer; translucent sensilla usually branched, rarely simply hairshaped (Fig. 2B). Palpus with 3 segments, first segment swollen, apical segment longest of all.

WING. ApicR 1 3.0-3.5 times as long as Rs. CuA reaches wing margin (Fig. 2D).

LEGS. Claws sickle-shaped, toothless. Empodia half as long as claws.

TERMinALIA. Ninth tergite long, posterior margin almost straight, posterolateral shoulders slightly apparent, anterior margin fully sclerotized (Fig. 2C). Gonocoxites (Fig. 2A): ventrobasal apodeme poorly sclerotized, especially anteriorly; medial extensions of gonocoxal apodemes weakly sclerotized, not interconnected medially. Gonostylus blunt-ended, $1+1$ short bristles among dense setulae and microtrichia apically, dorsoapical and ventrobasal portions same size (Fig. 2A). Tegmen slender, central opening inconspicuous, slit-like (Fig. 2A).

\section{Distribution and phenology}

This species is known from a small series of specimens collected in early June on Japan's highest mountain peak, Mount Fuji.

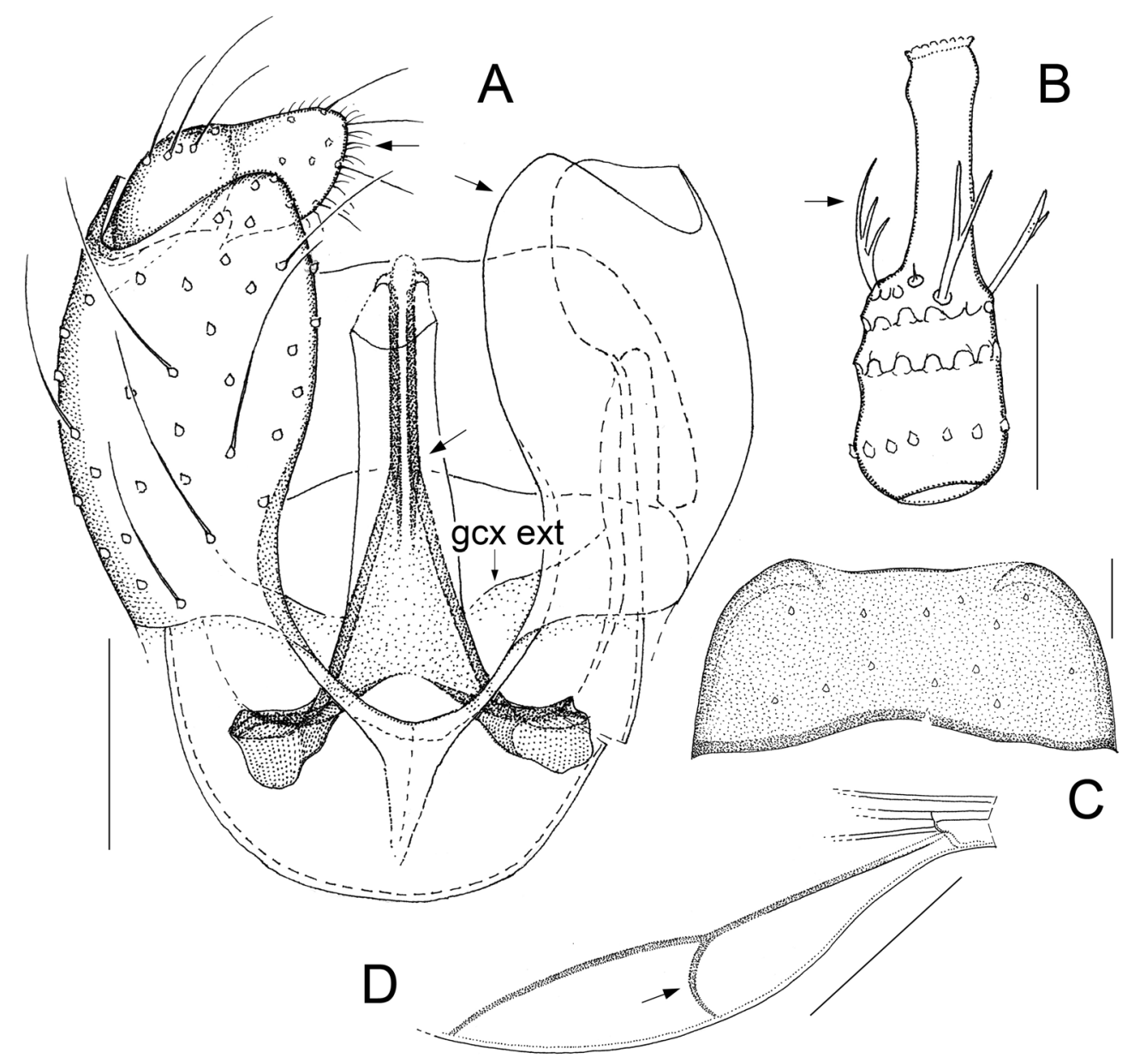

Fig. 2. Aprionus fujisanensis sp. nov., holotype, $\widehat{\partial}$. A. Genitalia, ventral. B. Fourth flagellomere, lateral. C. Ninth tergite, dorsal. D. Posterior portion of wing. Scale lines: A-B $=0.05 \mathrm{~mm}$; C $=0.025 \mathrm{~mm}$; D = $0.50 \mathrm{~mm}$. Arrows indicate diagnostic characters. 


\section{Aprionus ogawaensis sp. nov. \\ urn:lsid:zoobank.org:act:54A17E89-DFC6-409F-A02A-114016F8C423}

Fig. 3

\section{Diagnosis}

Aprionus ogawaensis sp. nov. is the only species of the angulatus group with a subanal plate, although weakly sclerotized and poorly contoured ( $\downarrow$, Fig. 3A). Other peculiarities are the gonocoxal apodemes lacking medial extensions and the tegminal pillars ending in small, posteriorly directed processes $(\downarrow$, Fig. 3A).

\section{Etymology}

The species epithet refers to Ogawa, a research forest in the Abukuma Highlands of Honshu, where all specimens known of this species were collected.

\section{Material examined}

\section{Holotype}

JAPAN: Ô, Honshu, Ibaraki, Kitaibaraki, Sadanami, Ogawa Research Forest, 600 m a.s.l., plantation of sugi (Cryptomeria japonica) interspersed with broadleaf trees, Malaise trap, K. Maeto leg., 27 May11 Jun. 1996 (KUEC, no. A7638).

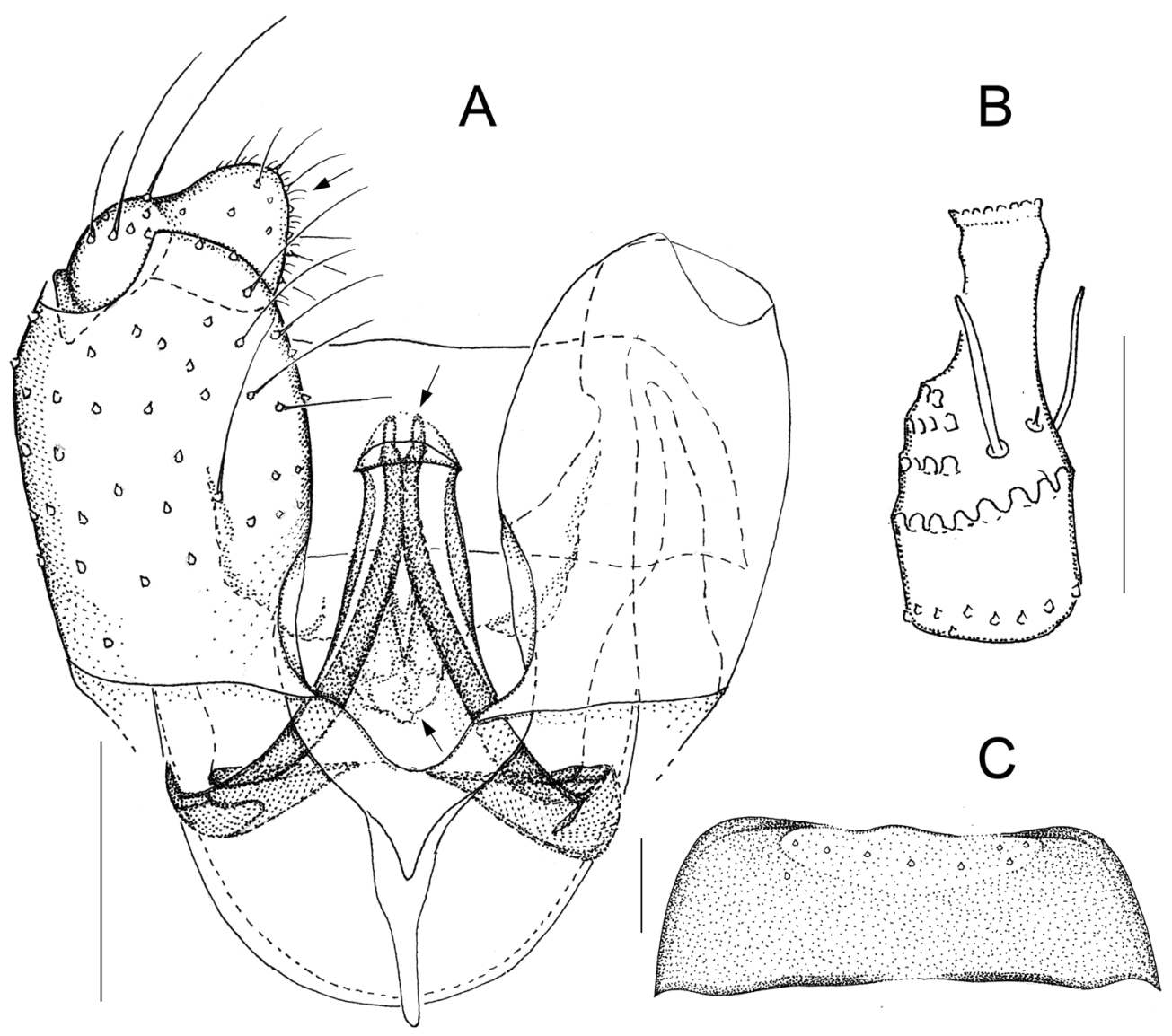

Fig. 3. Aprionus ogawaensis sp. nov., holotype, ô. A. Genitalia, ventral. B. Fourth flagellomere, lateral. C. Ninth tergite, dorsal. Scale lines: $0.05 \mathrm{~mm}$. Arrows indicate diagnostic characters. 
Paratypes

JAPAN: $3 \widehat{\partial} \widehat{\partial}$, same locality, but mature mixed broadleaf forest, MT, MCJ leg., 11 May-1 Jun. 1999 (DEI, nos A7639-A7641).

\section{Differential diagnosis}

The gonostylar apex in Aprionus ogawaensis sp. nov. is broadened ( $\downarrow$, Fig. 3A) but not to the same extent as in both A. denticulus Berest, 1986 (see Jaschhof 1998: fig. 172b) and A. marginatus Mamaev, 1963 (see Jaschhof \& Jaschhof 2009: fig. 75C). All other species of the angulatus group have narrow gonostylar apices (see Jaschhof \& Jaschhof 2009: fig. 75A-B, D-E).

\section{Other characters}

Body size $1.2-1.3 \mathrm{~mm}$.

HEAD. Eye bridge 2-3 ommatidia long dorsally. A dense row of 10-12 postocular bristles. Neck of fourth flagellomere shorter than node; translucent sensilla thick, simply hair-shaped (Fig. 3B). Palpus 4-segmented.

Wing. ApicR 1 2.5-3.5 times as long as Rs. CuA slightly curved, ends before wing margin.

Legs. Claws sickle-shaped, 1-2 fine teeth (hardly visible at times). Empodia half as long as claws.

TERMINALIA. Ninth tergite short, posterior margin slightly sinuous, anterior margin irregularly sclerotized, setae limited to a poorly sclerotized area medioposteriorly (Fig. 3C). Gonocoxites (Fig. 3A): ventroapical lobes small; ventrobasal apodeme strongly sclerotized, long, slender. Gonostylus blunt-ended, $2+1$ short bristles among dense setulae and microtrichia apically; dorsoapical portion larger than ventrobasal portion (Fig. 3A). Tegmen: lateral pillars thick, touching subapically; central opening small, without spinulae (Fig. 3A).

\section{Distribution and phenology}

This species is known from a single low-mountain site in central Honshu, Japan, where specimens were collected in late May to early June.

\section{The halteratus group}

Named after Aprionus halteratus (Zetterstedt, 1852), this species-rich group includes Aprionus with entire, toothed gonostyli and mostly finger-bearing tegmina (Jaschhof \& Jaschhof 2009: 243). The group is, by all indications, unlikely monophyletic. One indication is the great variation of morphological structure found within the group, which requires dividing it into several subgroups, with some species fitting in none of these. Another indication is the fact that in a part of the included species, tegminal fingers are vestigial or absent, which means an overlap with the smirnovi group (see below). Both the halteratus and smirnovi groups are maintained merely for practical reasons. The styloideus subgroup is introduced here as a monophyletic subset of the halteratus group.

\section{1) The insignis subgroup of the halteratus group}

In the species classified here, tegmina are lengthwise subdivided into a pair of cavities that contain the finger-like processes; the medial gonocoxal bridges have pointed projections ventromedially; and the subanal plate, which is weakly contoured, has only a few dark markings marginally (see Jaschhof \& Jaschhof 2009: 246). This subgroup is named after Aprionus insignis Mamaev, 1963. 


\section{Aprionus friggae sp. nov. urn:1sid:zoobank.org:act:79295AE9-F26E-480D-9E41-316740B9F808}

Fig. 4

\section{Diagnosis}

Male genitalic characters distinguish Aprionus friggae sp. nov. from other species of the insignis subgroup, as follows (Fig. 4A). The elongate gonostylus is provided with a small, flat tooth apically $(\downarrow)$; tegminal fingers $(\downarrow)$, present in two large, weakly contoured pairs, do not intersect medially due to their rearward orientation; and the posterior edge of the subanal plate has a V-shaped, sclerotized indentation $(\downarrow)$.

\section{Etymology}

Frigg, Odin's wife, is a goddess associated with foreknowledge and wisdom.

\section{Material examined}

\section{Holotype}

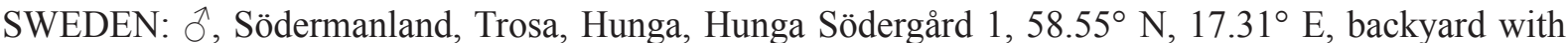
manure pile, Malaise trap, Swedish Malaise Trap Project (trap 12, collecting event 69), 24 Jun.5 Jul. 2003 (NHRS, no. CEC178).

\section{Paratypes}

SWEDEN: 2 ○े, Öland, Borgholm, Horns kungsgård NR, $57.20^{\circ} \mathrm{N}, 16.93^{\circ} \mathrm{E}$, mixed forest of birch, alder and willow trees at lakeside, MT, MCJ leg., 12 Jun.-20 Jul. 2015 (DEI, nos CEC301-CEC302); 1 ऽ, same data, but 23 Aug.-30 Sep. 2015 (NHRS, no. CEC179).

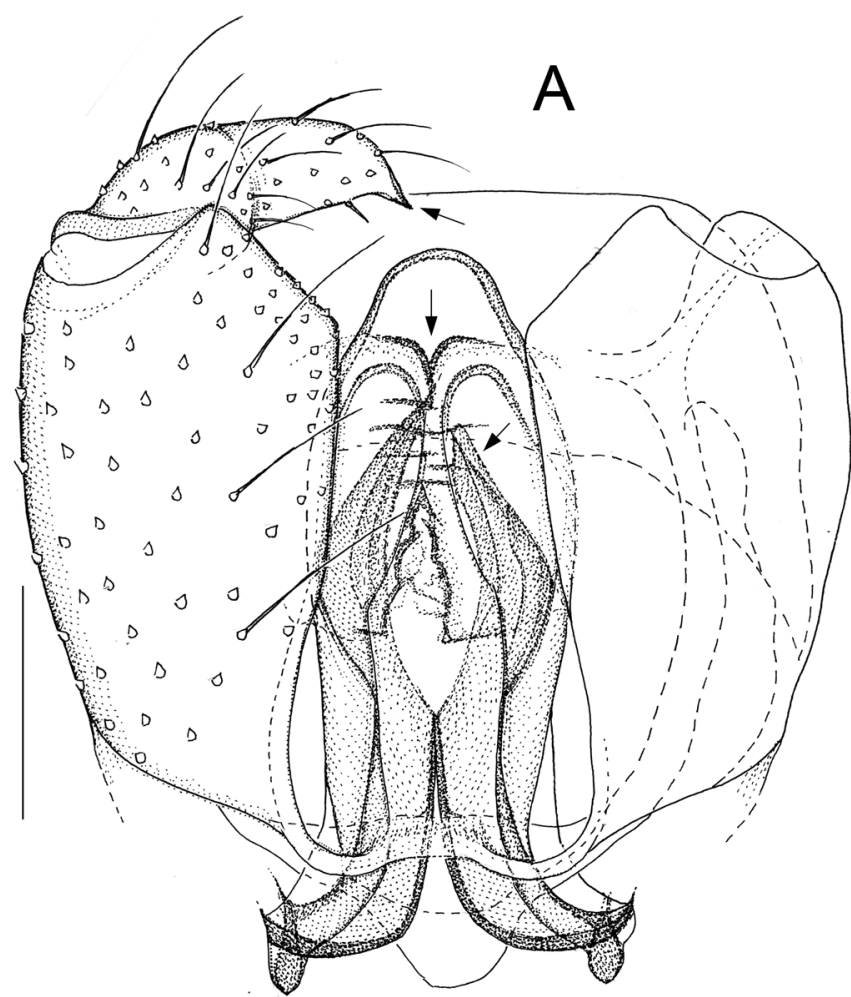

B

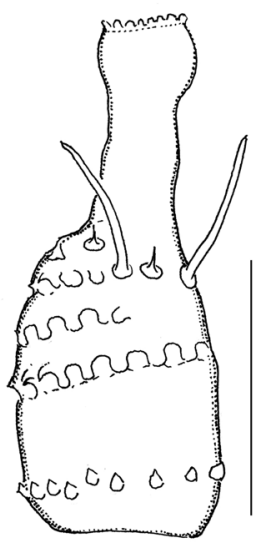

Fig. 4. Aprionus friggae sp. nov., §. A. Genitalia, ventral, holotype. B. Fourth flagellomere, lateral, paratype. Scale lines: $0.05 \mathrm{~mm}$. Arrows indicate diagnostic characters. 


\section{Differential diagnosis}

Aprionus friggae sp. nov. as characterized above is unmistakable, but, to avoid misidentification, should be compared with other species of the insignis subgroup with elongate (as opposed to stout, strongly convex) gonostyli, namely Aprionus longicollis Mamaev, 1963 (see Jaschhof 1998: fig. 162), A. sifae sp. nov. (described next), and A. taigaensis Jaschhof, 2009 (see Jaschhof \& Jaschhof 2009: fig. 83).

\section{Other characters}

Body size $1.2 \mathrm{~mm}$.

HEAD. Eye bridge 2-3 ommatidia long dorsally. A dense row of 9-10 postocular bristles. Neck of fourth flagellomere shorter than node; 3-4 thick, usually simply hair-shaped, rarely two-pointed translucent sensilla (Fig. 4B). Palpus with 3 segments, apical segment varying in length. In one of the specimens studied the two distal palpal segments are almost completely fused to form one single long entity.

WING. ApicR $13.5-4.5$ times as long as Rs.

LEGs. Claws subrectangular, 2 fine teeth. Empodia rudimentary.

Terminalia (Fig. 4A). Ninth tergite subrectangular, anterior margin fully sclerotized, concave medially. Gonocoxites pointed ventroposteriorly; projections of medial bridges indistinct; dorsal bridge small. Gonostylus thick and convex on basal half, elongate and tapered on apical half, apical tooth indistinct, 1-2 bristles subapicomedially, $0-1$ bristle subapicoposteriorly. Tegmen with 1-2 weak, small finger pairs in addition to large fingers, rounded apically. Subanal plate with indistinct dark markings along central axis.

\section{Distribution and phenology}

Sweden (Öland, Södermanland). Adults were collected from June to September, with the scarce collecting data providing no clue regarding any possible habitat preferences.

$$
\begin{aligned}
& \text { Aprionus sifae sp. nov. } \\
& \text { urn:1sid:zoobank.org:act:1F9333D3-0C73-49B6-AFC7-803A29D74286 }
\end{aligned}
$$

Fig. 5

\section{Diagnosis}

Aprionus sifae sp. nov. is tentatively classified in the insignis subgroup because of the outline of its subanal plate, the tegmen with slightly indicated twin-cavity structure, and the gonostyli resembling that of A. friggae sp. nov. An obvious distinction to other species of the halteratus group is that the tegminal fingers, present in 3-4 (rarely 2 or 5 ) pairs, are very small and point dorsally rather than laterally ( $\downarrow$, Fig. 5A).

\section{Etymology}

Sif, distinguished for her golden hair, is the wife of Thor.

\section{Material examined}

\section{Holotype}

SWEDEN: Ō, Öland, Mörbylånga, Ullevi, $56.37^{\circ} \mathrm{N}, 16.36^{\circ} \mathrm{E}$, herb-rich meadow near broadleaf forest, Malaise trap, M. and C. Jaschhof leg., 14 Jun.-15 Jul. 2015 (NHRS, no. CEC290). 
Paratypes

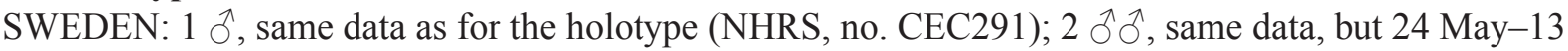
Jun. 2015 (NHRS, nos CEC292-293).

\section{Other material studied}

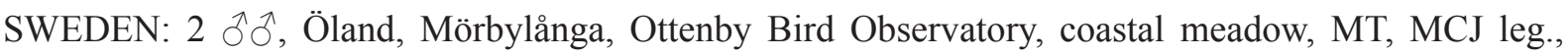
16 Jun.-8 Jul. 2015 (DEI, nos CEC294-CEC295).

\section{Other characters}

Body size 1.3-1.4 mm.

HEAD. Eye bridge 4 ommatidia long dorsally. A dense row of 9-10 postocular bristles. Neck of fourth flagellomere slightly longer than node; 3-4 thick translucent sensilla, usually simply hair-shaped, rarely two- to three-pointed (Fig. 5B). Palpus with 3 segments, apical segment slender, almost as long as first and second segments together.

WING. ApicR $13.0-4.0$ times as long as Rs.

Legs. Claws subrectangular, 2-3 fine teeth. Empodia rudimentary.

Terminalia (Fig. 5A). Ninth tergite subrectangular, anterior margin fully sclerotized, concave medially. Gonocoxites rounded to slightly pointed ventroposteriorly, depending on preparation; projections of medial bridges absent to slightly indicated; dorsal bridge small, typically subtriangular. Gonostylus thick and convex on basal half, elongate and tapered on apical half, apical tooth indistinct, 2 (rarely up

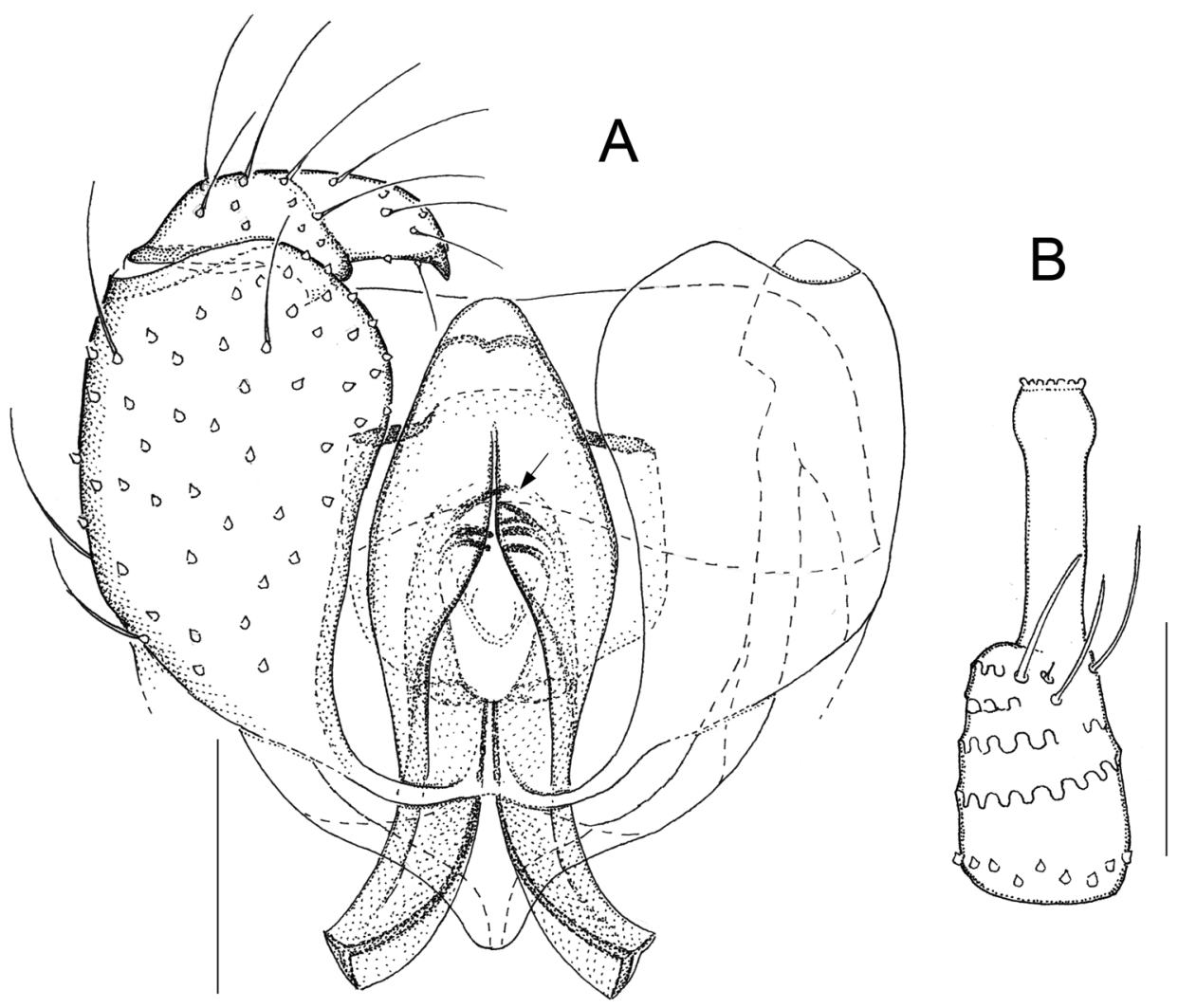

Fig. 5. Aprionus sifae sp. nov., holotype, $\widehat{\partial}$. A. Genitalia, ventral. B. Fourth flagellomere, lateral. Scale lines: $0.05 \mathrm{~mm}$. The arrow indicates an important diagnostic character. 
to 4) bristles subapicomedially. Tegmen rounded apically. Subanal plate subrectangular, with darkly marked shoulders posteriorly, indistinct variable dark markings elsewhere.

\section{Distribution and phenology}

Sweden (Öland). Adults were collected from May to July in various types of meadow.

Aprionus thori sp. nov.

urn:1sid:zoobank.org:act:80B22178-C33B-4E10-938D-3DF5E6819571

Fig. 6

\section{Diagnosis}

A typical representative of the insignis group, Aprionus thori sp. nov. is distinguished by the following male genitalic characters in combination (Fig. 6A): the gonostylus, which is strongly convex posteriorly, has a flat depression subapically above the tooth $(\downarrow)$; the tegmen, with 3-4 large finger pairs, is bluntended $(\downarrow)$; and the gonocoxal projections are prominent $(\downarrow)$.

\section{Etymology}

Thor, the god of thunder, is the son of Odin and his mistress, Jörd.

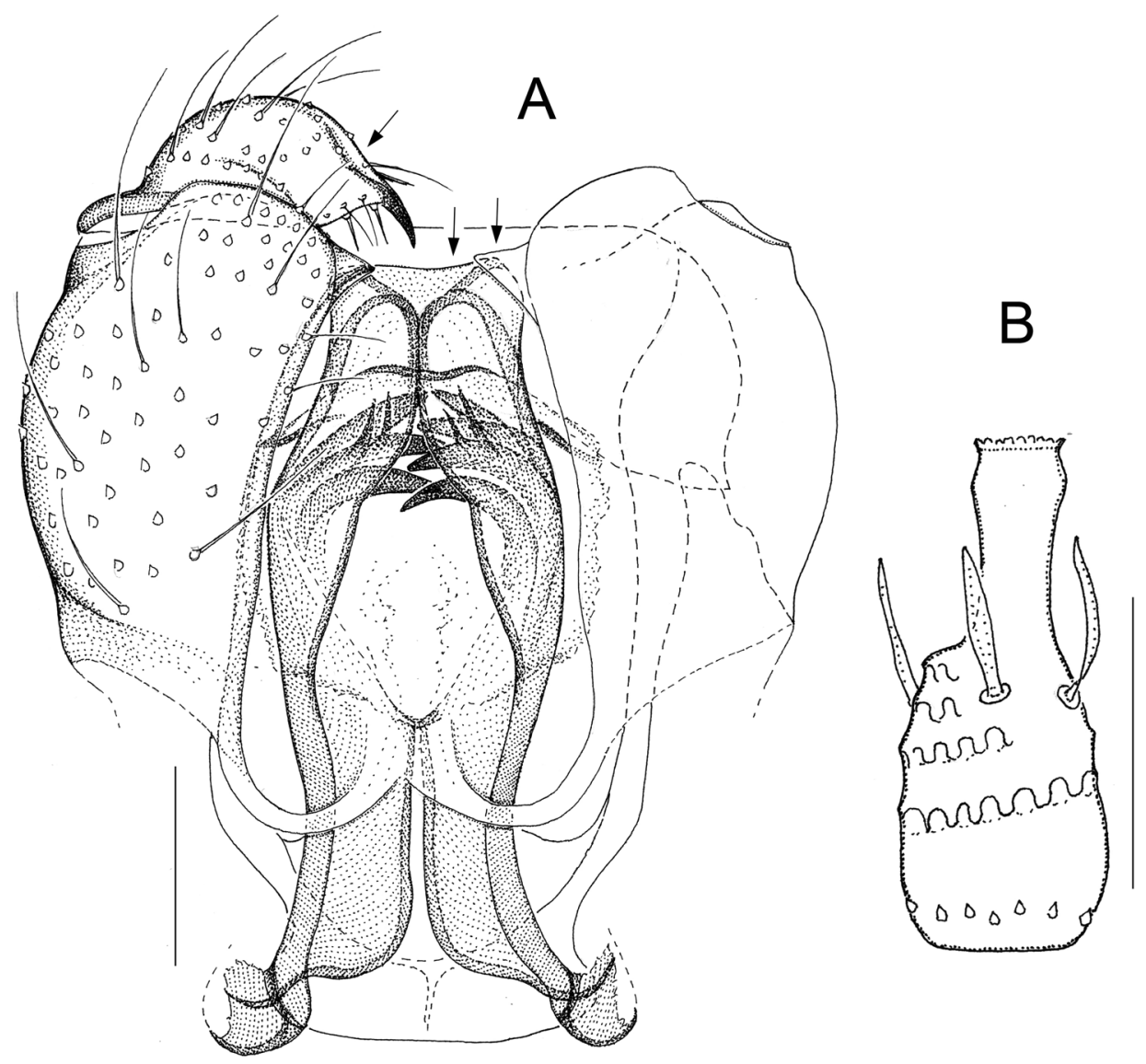

Fig. 6. Aprionus thori sp. nov., holotype, ô. A. Genitalia, ventral. B. Fourth flagellomere, lateral. Scale lines: $0.05 \mathrm{~mm}$. Arrows indicate diagnostic characters. 


\section{Material examined}

Holotype

SWEDEN: $\widehat{\partial}$, Småland, Nybro, Bäckebo, Grytsjön Nature Reserve, $56.92^{\circ} \mathrm{N}, 16.10^{\circ} \mathrm{E}$, tall coniferous forest with aspen trees, Malaise trap, M. and C. Jaschhof leg., 17 Jul.-21 Aug. 2015 (NHRS, no. CEC283).

\section{Paratypes}

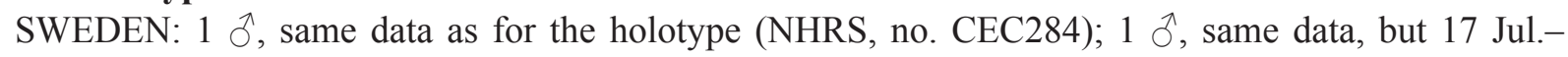
11 Aug. 2014 (NHRS, no. CEC285).

\section{Other material studied}

SWEDEN: 2 ○ð, Uppland, Uppsala, Fiby NR, $59.88^{\circ} \mathrm{N}, 17.34^{\circ} \mathrm{E}$, swampy mixed taiga, near aspen log, MT, MCJ leg., 9 Jun.-23 Jul. 2010 (DEI, nos CEC286-CEC287).

\section{Differential diagnosis}

Aprionus insignis, a species similar to Aprionus thori sp. nov., differs as follows: the gonostylus has no depression above the apical tooth; the tooth is smaller and flattened like a fingernail, not solid; the gonocoxal projections are smaller; and the tegmen, with only 2 finger pairs, is rounded apically (see Jaschhof 1998: fig. 161a-c).

\section{Other characters}

Body size $1.3 \mathrm{~mm}$.

HEAD. Eye bridge 3 ommatidia long dorsally. A dense row of 8-9 postocular bristles. Neck of fourth flagellomere shorter than node; 3-4 thick, simply hair-shaped translucent sensilla (Fig. 6B). Palpus with 3 segments, first segment slightly swollen, apical segment longest of all.

WING. ApicR $12-3$ times as long as Rs.

LEGs. Claws subrectangular, 2 fine teeth. Empodia rudimentary.

Terminalia (Fig. 6A). Ninth tergite subrectangular, anterior margin fully sclerotized, slightly concave medially. Gonocoxites slightly pointed ventroposteriorly; dorsal bridge massive, subrectangular. Gonostylus: basolateral apophysis conspicuously large; apical tooth solid, long, slightly curved; about 4 bristles subapicomedially, $0-1$ bristles subapicoposteriorly. Tegmen with slightly intersecting large fingers, additionally 1-3 tiny, non-intersecting finger pairs. Subanal plate with dark markings both laterally and medially on posterior edge, less clearly on anterior edge.

\section{Distribution and phenology}

Sweden (Småland, Uppland). Adults were collected from June to August; the circumstances of collecting suggest the larval habitat of this species might be rotting aspen wood.

\section{2) The styloideus subgroup of the halteratus group}

Aprionus styloideus Mamaev \& Berest, 1990, previously considered to belong to the brachypterus subgroup (Jaschhof \& Jaschhof 2009: 243), is shown here to be a complex of several, morphologically distinct species that are better classified in a subgroup of their own, the styloideus subgroup. As this renders Aprionus brachypterus Edwards, 1938 the only remaining member of the brachypterus subgroup, this subdivision is abandoned here, with A. brachypterus left unassigned to subgroup within the halteratus group (see Jaschhof \& Jaschhof 2009: 254). 
Species of the styloideus subgroup, of which most are extremely similar to each other, share the following characters: the elongate gonostyli are flattened to various extents; the tegmen has either 1-3 posteriorly oriented finger pairs or no fingers; the subanal plate is extremely weak posteriorly, with only the anterior corners clearly visible as dark, mostly comma-shaped areas dorsolateral of the tegmen; and antennal translucent sensilla are either simple or branched. Besides the species treated below, the styloideus subgroup contains Aprionus cardiophorus Mamaev, 1963 (a species classified by Jaschhof \& Jaschhof (2009) in the smirnovi group) and an unnamed species, of which our material is not sufficient for description. This subgroup is remarkable for including species that either possess or lack tegminal fingers, which indicates the weakness of this character as an indicator of relatedness.

Aprionus hugini sp. nov. urn:1sid:zoobank.org:act:431B8648-300E-4873-97C0-515CF228875D

Fig. 7

\section{Diagnosis}

The strongly flattened gonostylus is twice as long as wide; its basal half is only slightly convex; the basolateral apophysis is small; and the large tooth is inserted not exactly on the apex but slightly more dorsolaterally ( $\downarrow$, Fig. 7A). The medial gonocoxal bridges protrude to form subtriangular protuberances $(\downarrow)$, which in related species are much smaller and rounded. The tegmen, which is 2.5 times as long as wide, is broadest beyond the midlength $(\downarrow)$; tegminal fingers, present in 2-4 large pairs, are situated far posteriorly and point laterally rather than posteriorly; the apex of the tegmen is broadly rounded. The sclerotized, anterolateral portions of the subanal plate are distinct, large, and usually perfectly commashaped $(\downarrow)$. As regards the gonocoxites, the dorsal apodemes are so long that the dorsal bridge, which in the typical outline is subtriangular, extends clearly beyond the ventroanterior edge. The postfrons is setose; most of the antennal translucent sensilla are single-pointed, others, especially on proximal

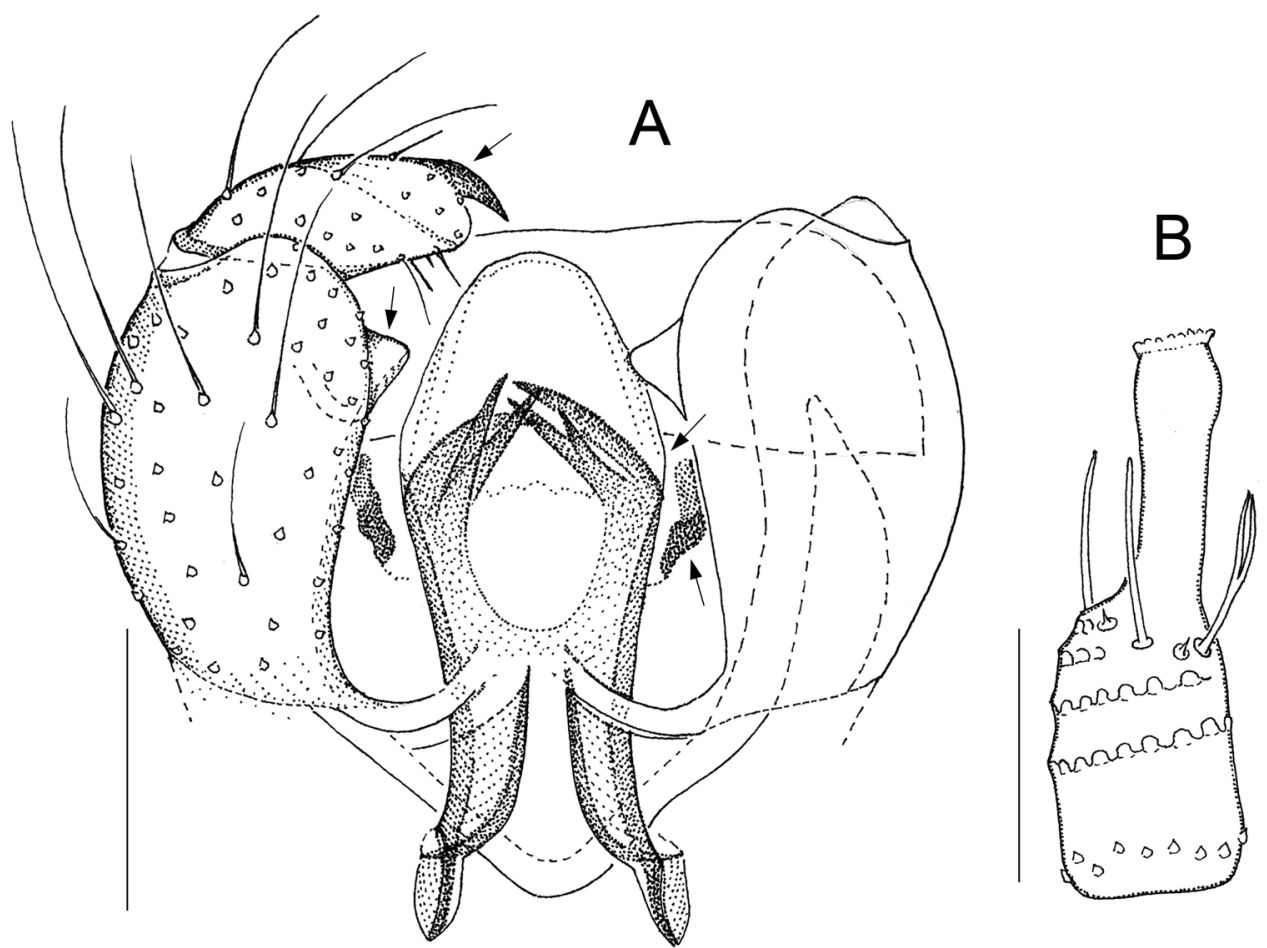

Fig. 7. Aprionus hugini sp. nov., holotype, $\widehat{\partial}$. A. Genitalia, ventral. B. Fourth flagellomere, lateral. Scale lines: $0.05 \mathrm{~mm}$. Arrows indicate diagnostic characters. 
flagellomeres, two-pointed or two-branched; the neck of the fourth flagellomere is slightly shorter to slightly longer than the node (Fig. 7B); the palpus consists of 4 segments; and postocular bristles number $8-10$.

\section{Etymology}

Hugin is one of Odin's two ravens, which serve him as rapporteurs and help compensate his poor eyesight.

\section{Material examined}

\section{Holotype}

SWEDEN: ${ }^{\Uparrow}$, Östergötland, Ödeshög, Omberg, Stocklycke meadow, $58.18^{\circ} \mathrm{N}, 14.37^{\circ}$ E, calcareous meadow, Malaise trap, Swedish Malaise Trap Project (trap 13, collecting event 909), 25 May-8 Jun. 2003 (NHRS, no. CEC340).

\section{Paratypes}

SWEDEN: $11 \hat{\partial} \hat{\partial}$, same data as for the holotype (NHRS, nos CEC341-CEC351); $6 \hat{\partial} \hat{\sigma}$, same data (collecting event 1647), but 2-23 Aug. 2005 (NHRS, nos CEC352-CEC357); 1 ô, same data (collecting event 1644), but 12-20 Jul. 2005 (NHRS, no. CEC358).

\section{Other material studied}

SWEDEN: 1 ○े, Östergötland, Ödeshög, Omberg, Beech NR, $58.17^{\circ} \mathrm{N}, 14.38^{\circ}$ E, beech forest, MT, SMTP (trap 16, collecting event 1667), 5-19 Jul. 2005 (DEI, no. CEC359); 1 đ, Småland, Nybro, Bäckebo, Grytsjön NR, $56.92^{\circ} \mathrm{N}, 16.10^{\circ}$ E, swampy meadow at forest edge, MT, MCJ leg., 17 Jun.-16 Jul. 2015 (DEI, no. CEC360); 1 §ె, Öland, Mörbylånga, Ottenby, Södra lunden, $56.13^{\circ} \mathrm{N}, 16.25^{\circ} \mathrm{E}$, nemoral grove, MT, SMTP (trap 21, collecting event 993), 23 Jun.-26 Jul. 2005 (DEI, no. CEC361).

GERMANY: 1 ก, Mecklenburg-Vorpommern, Galenbecker See, $11 \mathrm{~km}$ SE of Friedland, swampy birch forest, aspirator, MJ leg., 10 Jun. 1994 (DEI, no. A2309); 1 ภ, same locality data, but swampy meadow, yellow pan trap, 25-27 May 1994 (DEI, no. A2320); 1 ô, same data, but ground emergence trap, Jun. 1994 (DEI, no. A2321).

\section{Differential diagnosis}

Aprionus hugini sp. nov. is distinguished from the other species of the styloideus group in the medial gonocoxal bridges, which protrude strongly, and in the characteristic outline of the tegmen, as described above. The gonostylus of Aprionus hugini sp. nov. resembles that of A. paludosus Jaschhof \& Mamaev, 1997 stat. rev., a species redescribed below, except that in A. paludosus the basolateral apophysis is larger, or normally developed.

\section{Distribution and phenology}

Sweden (Småland, Öland, Östergötland), Germany (Mecklenburg-Vorpommern). Adults were collected in May to August mainly in swampy meadows, the habitat apparently preferred by this species.

Aprionus munini sp. nov. urn:lsid:zoobank.org:act:BBBCB884-E291-4AC9-A9F2-54296E78781E

Fig. 8

\section{Diagnosis}

The gonostylus is broad and slightly convex basally, then evenly tapered towards the narrow apex ( $\downarrow$, Fig. 8A), and provided with a moderately large tooth apically. The tegmen, which is $2.8-3.0$ times as long 
as wide, is broadest at or slightly below the midlength; the 2-3 large finger pairs, which are situated far posteriorly, intersect only slightly $(\downarrow)$ or not at all; the tegminal apex is blunt-ended $(\downarrow)$. There may be an exceptional 5 fingers on the one side and 3 fingers on the other side of the tegmen. The sclerotized areas at the anterior corners of the subanal plate are large but often rather weak. The gonocoxal apodemes are so short that the dorsal bridge, which often is slightly rectangular, extends to about the same level like the ventroanterior gonocoxal edge. The postfrons is unsetose; antennal translucent sensilla are almost always single-pointed, exceptionally two-pointed; the neck of the fourth flagellomere is longer than the node (Fig. 8B); the palpus is 3-segmented; and postocular bristles number 5-6(-7).

\section{Etymology}

Munin is the other of the two ravens accompanying Odin.

\section{Material examined}

\section{Holotype}

SWEDEN: O̊ Öland, Mörbylånga, Ullevi, $56.37^{\circ} \mathrm{N}, 16.36^{\circ} \mathrm{E}$, herb-rich meadow at forest edge, Malaise trap, M. and C. Jaschhof leg., 14 Jun.-15 Jul. 2015 (NHRS, no. CEC332).

\section{Paratypes}

SWEDEN: 1 đે, Öland, Mörbylånga, Gamla Skogsby, $56.37^{\circ} \mathrm{N}, 16.30^{\circ} \mathrm{E}$, scrubby meadow at forest edge ('diversity meadow'), MT, MCJ leg., 30 Apr.-8 Jun. 2015 (NHRS, no. CEC333); 1 ô, same data, but 7-29 Jul. 2015 (NHRS, no. CEC334); 1 Oे, Mörbylånga, Västerstad elm-forest NR, $56.42^{\circ} \mathrm{N}$, $16.42^{\circ} \mathrm{E}$, mature elm forest, MT, MCJ leg. and SMTP (trap 3002, collecting event 3053), 10 Jun.9 Jul. 2014 (NHRS, no. CEC335).
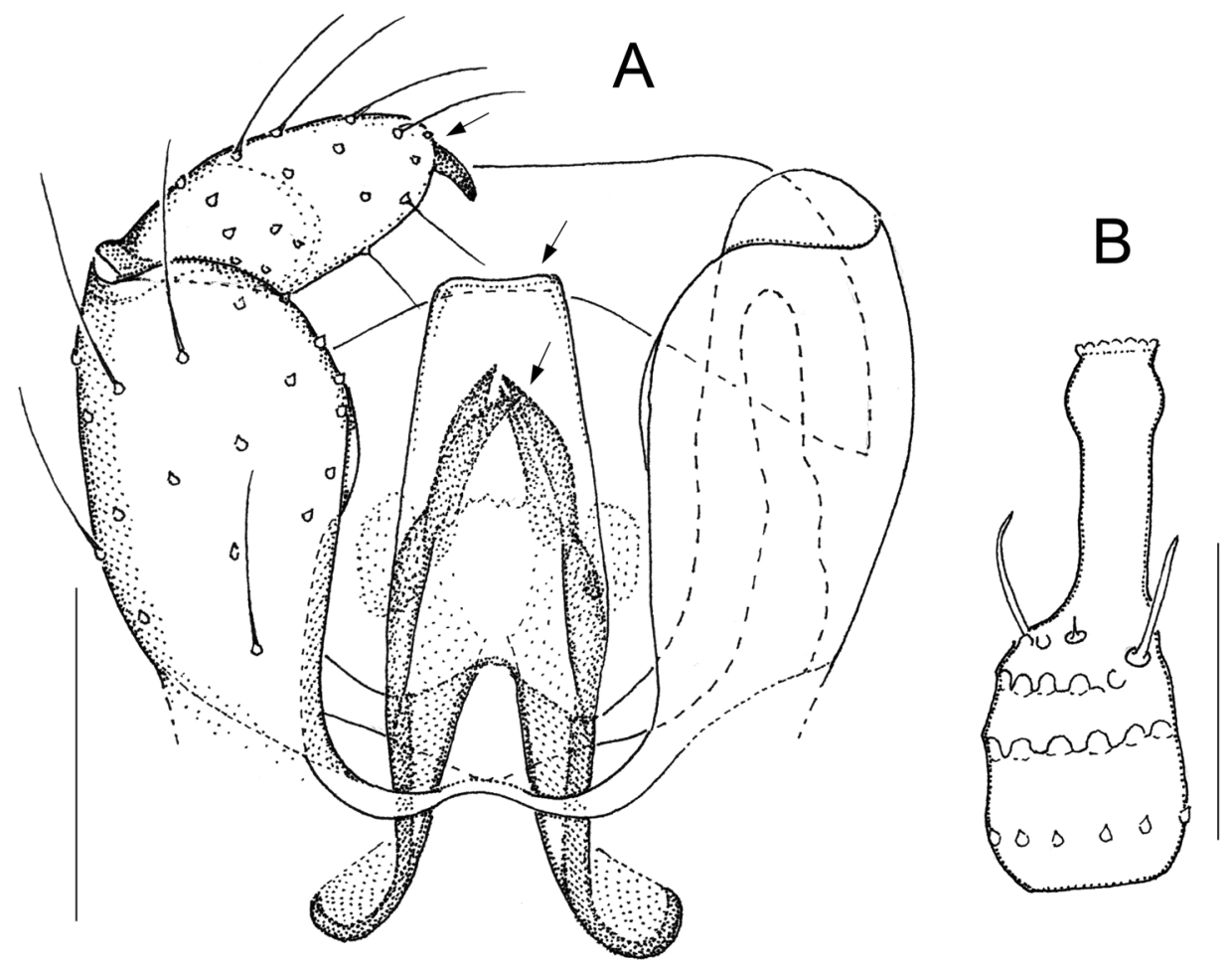

Fig. 8. Aprionus munini sp. nov., ふै. A. Genitalia, ventral, holotype. B. Fourth flagellomere, lateral, paratype. Scale lines: $0.05 \mathrm{~mm}$. Arrows indicate diagnostic characters. 


\section{Other material studied}

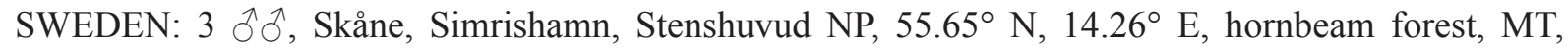
MCJ leg., 16 Jun.-1 Sep. 2009 (NHRS, nos CEC336-CEC338); 1 §ิ, Uppland, Håbo, Biskops Arnö, $59.40^{\circ} \mathrm{N}, 17.30^{\circ} \mathrm{E}$, elm groove, MT, SMTP (trap 8, collecting event 1558), 28 Jun.-13 Jul. 2004 (NHRS no. CEC339).

GERMANY: $2 \hat{\jmath}$, Brandenburg, Barnim, Klein Ziethen, Schorfheide-Chorin Biosphere Reserve, Serwester See, Kernberge, meadow near pine forest, MT, 15 Jun. and 8 Jul. 2004 (DEI, nos A7669A7670); 1 đ, Bavaria, Oberpfalz, Neumarkt, Main-Donau-Kanal, Warncke Project, 15-30 May 1988 (DEI, no. A7671); 1 స̃, Baden-Württemberg, Malsch, Kieswerk Glaser, edge of pine forest, MT, D. Doczkal leg., 21 Apr.-8 May 2010 (DEI, no. A7672); 1 §ૈ, Baden-Württemberg, Sandweier near Baden-Baden, meadow at edge of oak forest, MT, D. Doczkal leg., 1 Sep.-1 Oct. 2009 (DEI, no. A7673); 1 , same data, but xeric grassland at edge of birch forest (DEI, no. A7674); 1 o, same data, but 14 Aug.-1 Sep. 2009 (DEI, no. A7675).

HUNGARY: 1 §ૈ, Komitate Borsod-Abaúj-Zemplén, Aggteleki Nemzeti Park, Aggteleki, 290 m a.s.l., yellow pan trap, B. Rulik leg., 23-26 May 1998 (DEI, no. A7169).

\section{Differential diagnosis}

Aprionus munini sp. nov. is distinguished from A. styloideus, a very similar species redescribed below, by the broader gonostyli; the longer, blunt-ended tegmen; the unsetose postfrons; and palpi with always 3 segments.

\section{Distribution and phenology}

Sweden (Skåne, Öland, Uppland), Germany (Brandenburg, Bayern, Baden-Württemberg), Hungary. Adults were collected in May to October mainly in meadows and open woodland. This species appears to prefer xerothermic habitats.

Aprionus odini sp. nov. urn:1sid:zoobank.org:act:58A9F002-97C7-4794-8C5D-6238685DE080

Fig. 9

\section{Diagnosis}

The gonostylus has a characteristic, large, rounded lobe subapicomedially ( $\downarrow$, Fig. 9A), a clearly convex basal portion, a small basolateral apodeme, and a moderately large tooth apically. The tegmen is 3.5 times as long as wide, therefore longer than in any other species of the styloideus group, and evenly tapered towards the apex; large finger pairs are absent, but there are numerous tiny little finger vestiges dorsosubapically $(\downarrow)$. The anterior corners of the subanal plate are visible as two weakly contoured rectangles, each with a comma-shaped sclerotization $(\downarrow)$. The gonocoxal apodemes are so long that the dorsal bridge, which is subtriangular, extends far beyond the ventroanterior gonocoxal edge $(\downarrow)$. The postfrons bears a single pair of setae; antennal translucent sensilla are either single-pointed or two- to three-pointed, or -branched; the neck of the fourth flagellomere is longer than the node (Fig. 9B); the palpus is 4-segmented; and postocular bristles number 8-10.

\section{Etymology}

Odin, depicted as one-eyed and accompanied by various animal companions, is the god associated with healing, death, knowledge, sorcery, battle, and more. 


\section{Material examined}

\section{Holotype}

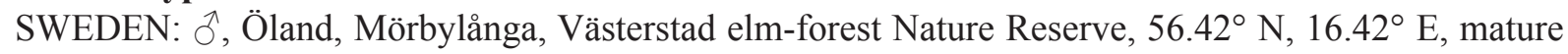
elm forest, Malaise trap, M. and C. Jaschhof leg. with the Swedish Malaise Trap Project (trap 3001, collecting event 3056), 6 Aug.-6 Sep. 2014 (NHRS, no. CEC193).

\section{Paratypes}

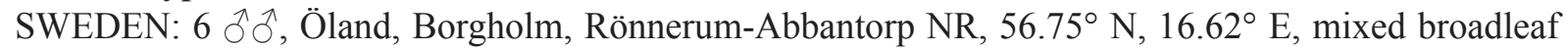
forest, MT, MCJ leg., 22 Aug.-30 Sep. 2015 (NHRS, nos CEC362-CEC367).

\section{Other material studied}

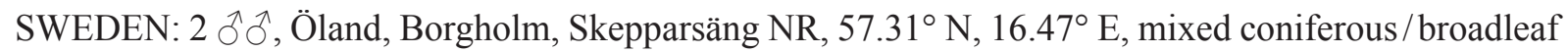
forest, MT, MCJ leg., 24 Aug.-1 Oct. 2015 (DEI, nos CEC368-CEC369); 2 ふో , Öland, Mörbylånga, Färjestaden, $56.63^{\circ} \mathrm{N}, 16.47^{\circ} \mathrm{E}$, backyard with shrub and young birch trees, MT, MCJ leg., 19 Aug.6 Oct. 2015 (DEI, nos CEC370-CEC371).

\section{Differential diagnosis}

A species very similar to Aprionus odini sp. nov. is Aprionus cardiophorus, which differs in the gonostylus lacking a subapical lobe and the tegmen constricted subapically and lacking finger vestiges (Spungis \& Jaschhof 2000: fig. 6).

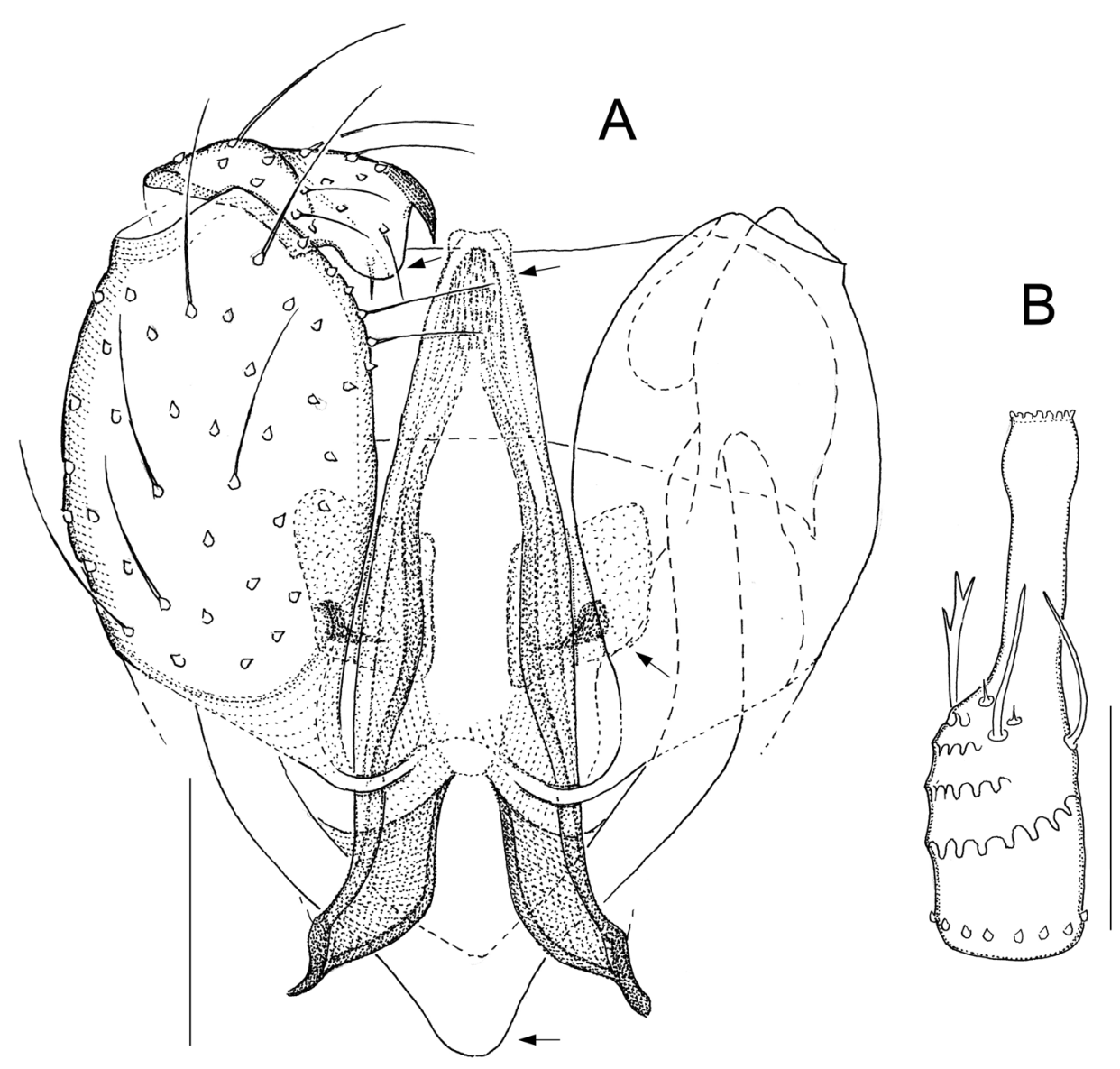

Fig. 9. Aprionus odini sp. nov., holotype, ${ }^{\lambda}$. A. Genitalia, ventral. B. Fourth flagellomere, lateral. Scale lines: $0.05 \mathrm{~mm}$. Arrows indicate diagnostic characters. 


\section{Distribution and phenology}

Sweden (Öland). Adults were collected from August to October in various different woodlands.

\section{Aprionus paludosus Jaschhof \& Mamaev, 1997 stat. rev.}

Fig. 10

Aprionus paludosus is revived here from synonymy with $A$. styloideus, which reverses our previous decision on the identity of these two species, while the synonymy of Aprionus bicuspidatus Mamaev, 1998 with A. paludosus is confirmed (see Jaschhof \& Jaschhof 2009: 243). Our present study revealed A. paludosus to be the most common and most widespread species of the styloideus group.

\section{Diagnosis}

The gonostylus (Fig. 10A) is strongly flattened, slightly convex basally, and twice as long as wide, the width being constant from the base to the apex; the basolateral apophysis is of normal size; the large tooth is inserted slightly dorsolaterally rather than right on the apex $(\downarrow)$. The tegmen, which is 2.7 times as long as wide, is broadest below the midlength $(\downarrow)$; the 2-3 pairs of large fingers intersect slightly $(\downarrow)$; the tegminal apex is rounded, seldom more blunt. The anterior corners of the subanal plate have small, dot-like sclerotizations, sometimes surrounded by larger, subrectangular, weakly sclerotized portions $(\downarrow)$. The gonocoxal apodemes are so long that the dorsal bridge, which is narrowly rounded, extends clearly beyond the ventroanterior gonocoxal edge $(\downarrow)$. The postfrons is setose; antennal translucent sensilla are single-pointed; the neck of the fourth flagellomere is shorter than the node (Fig. 10B); the palpus is 4-segmented (if 3-segmented, then the apical segment is clearly the result of two fused segments); and postocular bristles number 9-11.
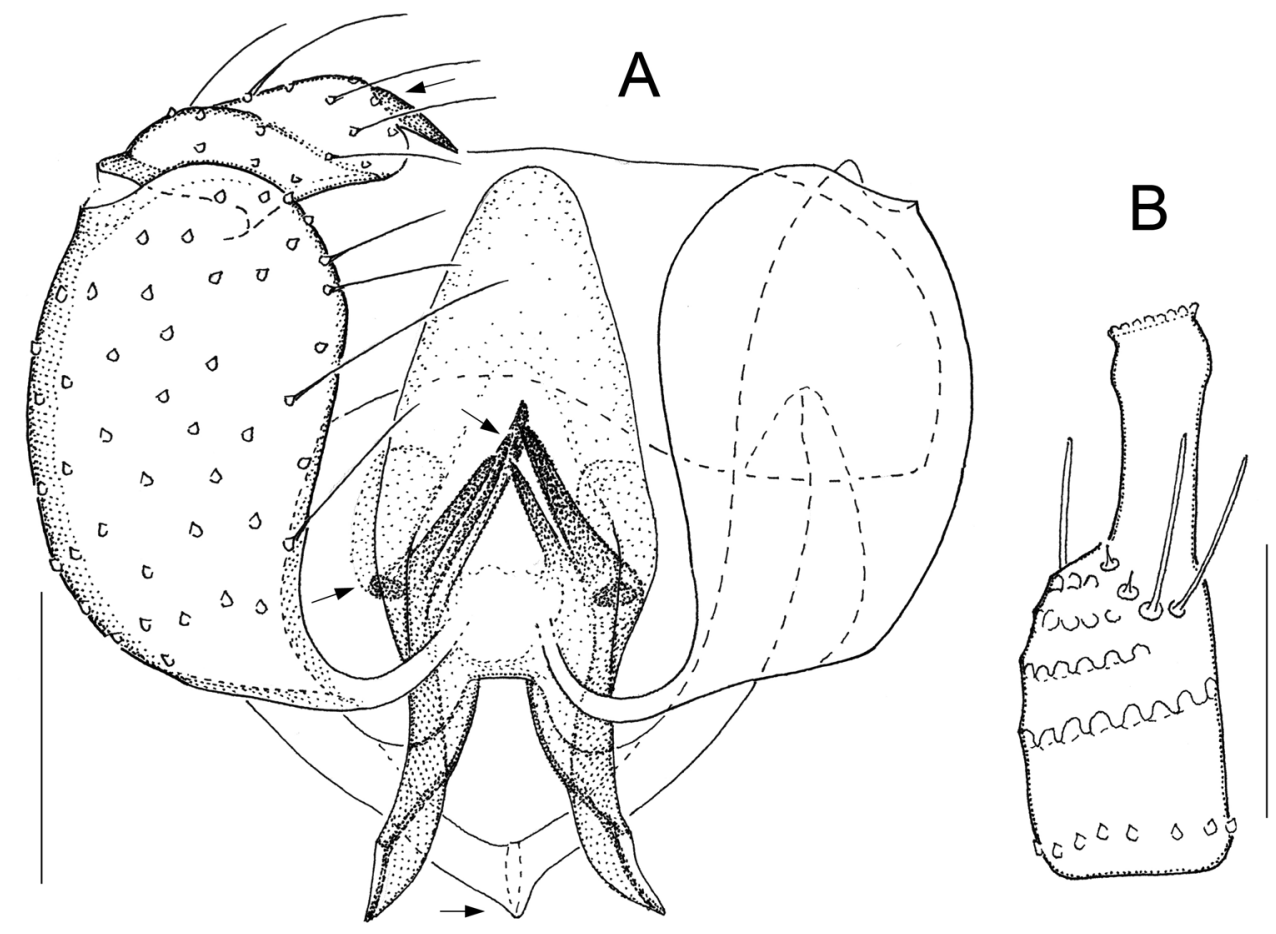

Fig. 10. Aprionus paludosus Jaschhof \& Mamaev, 1997, paratype, đ̊. A. Genitalia, ventral. B. Fourth flagellomere, lateral. Scale lines: $0.05 \mathrm{~mm}$. Arrows indicate diagnostic characters. 


\section{Material examined}

Specimens (incl. types) in DEI listed by Jaschhof (1998), specimens in NHRS listed by Jaschhof \& Jaschhof (2009).

SWEDEN: 1 đิ, Skåne, Klippans, Skäralid, Liema, beech forest, MT, SMTP (trap 37, collecting event 831), 20 May-11 Jun. 2004 (no. CEC328); 1 § , Uppland, Uppsala, Fiby NR, 59.72 ${ }^{\circ}$ N, $17.34^{\circ}$ E, mixed swampy taiga, MT, MCJ leg., 23 Jun.-28 Jul. 2009 (no. CEC329); 1 ภ̄, Uppland, Älvkarleby, Båtfors, $60.27^{\circ} \mathrm{N}, 17.19^{\circ} \mathrm{E}$, blueberry-pine forest, MT, SMTP (trap 7, collecting event 378), 17 Jun.-3 Jul. 2003 (no. CEC330); 1 $\widehat{\jmath}$, Lule Lappmark, Sorsele, Vindelfjällen NR, $6 \mathrm{~km} \mathrm{~W}$ of Ammarnäs, herb-rich subalpine birch forest, MT, MCJ leg., 7 Jul.-12 Aug. 2009 (no. CEC331).

\section{Distribution and phenology}

Norway, Sweden (Skåne, Södermanland, Uppland, Dalarna, Västerbotten, Lule Lappmark, Pite Lappmark, Norrbotten), Finland, Germany (Schleswig-Holstein, Mecklenburg-Vorpommern), European Russia; presumably more widespread, with records in literature (see Jaschhof \& Jaschhof 2009, as A. styloideus) from Denmark, Latvia, Estonia, and the East Palaearctic in need of validation. Adults were collected from May to August in various types of forest, with some preference of swampy sites.

$$
\begin{gathered}
\text { Aprionus sleipniri sp. nov. } \\
\text { urn:lsid:zoobank.org:act:858990F3-8AB7-4B04-9CC7-368F916028F7 }
\end{gathered}
$$

Fig. 11

\section{Diagnosis}

Aprionus sleipniri sp. nov. is distinguished from all other Aprionus, including the styloideus group, by the tegmen whose narrowly rounded apex is strongly sclerotized ( $\downarrow$, Fig. 11A). In lateral view it

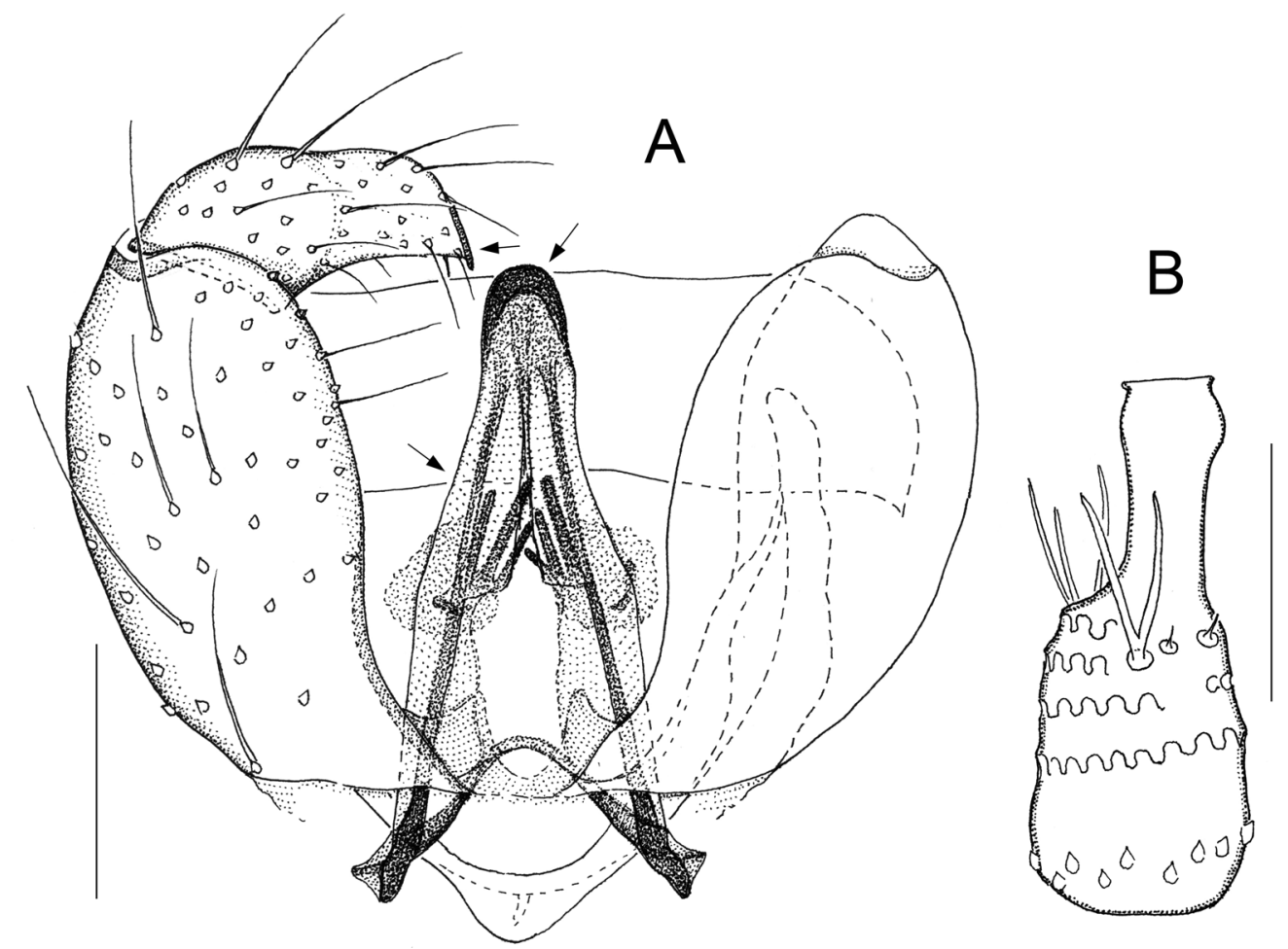

Fig. 11. Aprionus sleipniri sp. nov., ô. A. Genitalia, ventral, holotype. B. Fourth flagellomere, lateral, paratype. Scale lines: $0.05 \mathrm{~mm}$. Arrows indicate diagnostic characters. 
is obvious that this sclerotized cap transitions smoothly into the membranous portion of the aedeagus ventrally of the tegmen. The 2-4 pairs of short tegminal fingers are directed posteriorly rather than laterally, so intersect only slightly or not at all $(\downarrow)$. The gonostylar tooth $(\downarrow)$, which is shaped like a fingernail, is much smaller than that found in the other species of the styloideus group. As an unusual condition in Aprionus, the ventral gonocoxal bridge is membranous, not made of a thin, sclerotized bar.

\section{Etymology}

Sleipnir is Odin's eight-legged horse.

\section{Material examined}

\section{Holotype}

SWEDEN: ${ }^{\lambda}$, Öland, Mörbylånga, Västerstad elm-forest Nature Reserve, $56.42^{\circ} \mathrm{N}, 16.42^{\circ} \mathrm{E}$, mature elm forest, sweepnet and aspirator, M. and C. Jaschhof leg., 9 Jun. 2014 (NHRS, no. CEC169).

\section{Paratypes}

SWEDEN: $5 \widehat{\jmath}$, same data as for the holotype (NHRS, nos CEC170-CEC174).

\section{Other material studied}

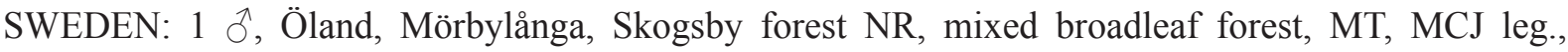
13 May-9 Jun. 2015 (DEI, no. CEC372); 1 ô, Öland, Stora Dalby forest NR, $56.47^{\circ} \mathrm{N}, 16.45^{\circ} \mathrm{E}$, mixed broadleaf forest, MT, MCJ leg., 5 May.-7 Jun. 2015 (DEI, no. CEC373).

\section{Other characters}

Body size 1.1-1.2 mm.

HEAD. Postfrons setose. Eye bridge 2-3 ommatidia long dorsally. A dense row of 8-9 postocular bristles. Neck of fourth flagellomere shorter than node, 3-4 thick translucent sensilla, either simply hair-shaped or two- to three-branched (Fig. 11B). Palpus 3-segmented, length of segments varying.

WING. ApicR 1 2.0-2.5 times as long as Rs.

Legs. Claws slightly bent, 2 fine teeth. Empodia rudimentary.

Terminalia (Fig. 11A). Ninth tergite short, subrectangular, anterior margin straight, fully sclerotized. Dorsal gonocoxal bridge typically subtriangular, extends beyond ventroanterior gonocoxal edge. Gonostylus elongate, convex on basal half portion, basolateral apophysis poorly developed. Tegmen as long as gonocoxites, evenly tapered towards apex. Anterior corners of subanal plate apparent as poorly defined, weakly sclerotized areas with dark centers.

\section{Distribution and phenology}

Sweden (Öland). Adults were collected in May and June in broadleaf forests.

Aprionus styloideus Mamaev \& Berest, 1990

Fig. 12

Aprionus styloideus, originally described from Ukraine, was previously thought to be synonymous with A. paludosus, based on the misapprehension that the holotype was just a slightly aberrant specimen (see Jaschhof \& Jaschhof 2009: 244). Specimens now at our disposal, more than 20 from different localities in Sweden and Germany, display exactly the same morphological peculiarities found in the 
holotype of $A$. styloideus. This we think is convincing evidence that $A$. styloideus is a species distinct from $A$. paludosus.

\section{Diagnosis}

The most important distinction is the shape of the gonostylus, which is only slightly convex and narrow basally, then evenly tapered towards the apex, and without a broadening at the base of the apical tooth ( $\downarrow$, Fig. 12A); altogether this results in a slender appearance. The size of the gonostylar tooth is subject to some variation, but may also depend on the viewing angle. The tegmen is 2.5 times as long as wide, thus shorter than in most other group members, with the greatest width found at about the midlength; the 1-2 large and 1-2 small finger pairs are essentially posteriorly oriented, so that fingers intersect only slightly $(\downarrow)$ or not at all; the tegminal apex is rounded $(\downarrow)$, occasionally blunt-ended. The minimum observed in our specimens is 1 pair each of large and small, non-intersecting fingers, which is exactly the condition in the holotype. The sclerotizations at the anterior corners of the subanal plate are large and commashaped $(\downarrow)$. The gonocoxal apodemes are so short that the dorsal bridge, which is broadly rounded, extends only slightly, or not at all, beyond the ventroanterior gonocoxal edge $(\downarrow)$. The postfrons bears a single pair of setae; antennal translucent sensilla are single-pointed; the neck of the fourth flagellomere is longer than the node (Fig. 12B); the palpus may be either 3- or 4-segmented; and postocular bristles number 6-7.

\section{Material studied}

SWEDEN (10 specimens in NHRS, 9 in DEI): 1 đ, Öland, Mörbylånga, Stora Dalby forest NR, $56.47^{\circ}$ N, $16.45^{\circ} \mathrm{E}$, mixed broadleaf forest, MT, MCJ leg., 8 Jun. -8 Jul. 2015 (no. CEC309); 3 ổ, Mörbylånga, Vickleby ädellövskog NR, $56.59^{\circ} \mathrm{N}, 16.43^{\circ} \mathrm{E}$, mixed broadleaf forest, MT, MCJ leg., 15 Jul.-3 Oct. 2015 (nos CEC310-CEC312); 1 సै, Mörbylånga, Gamla Skogsby, $56.61^{\circ} \mathrm{N}, 16.51^{\circ} \mathrm{E}$, mixed broadleaf

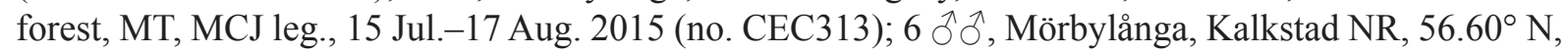
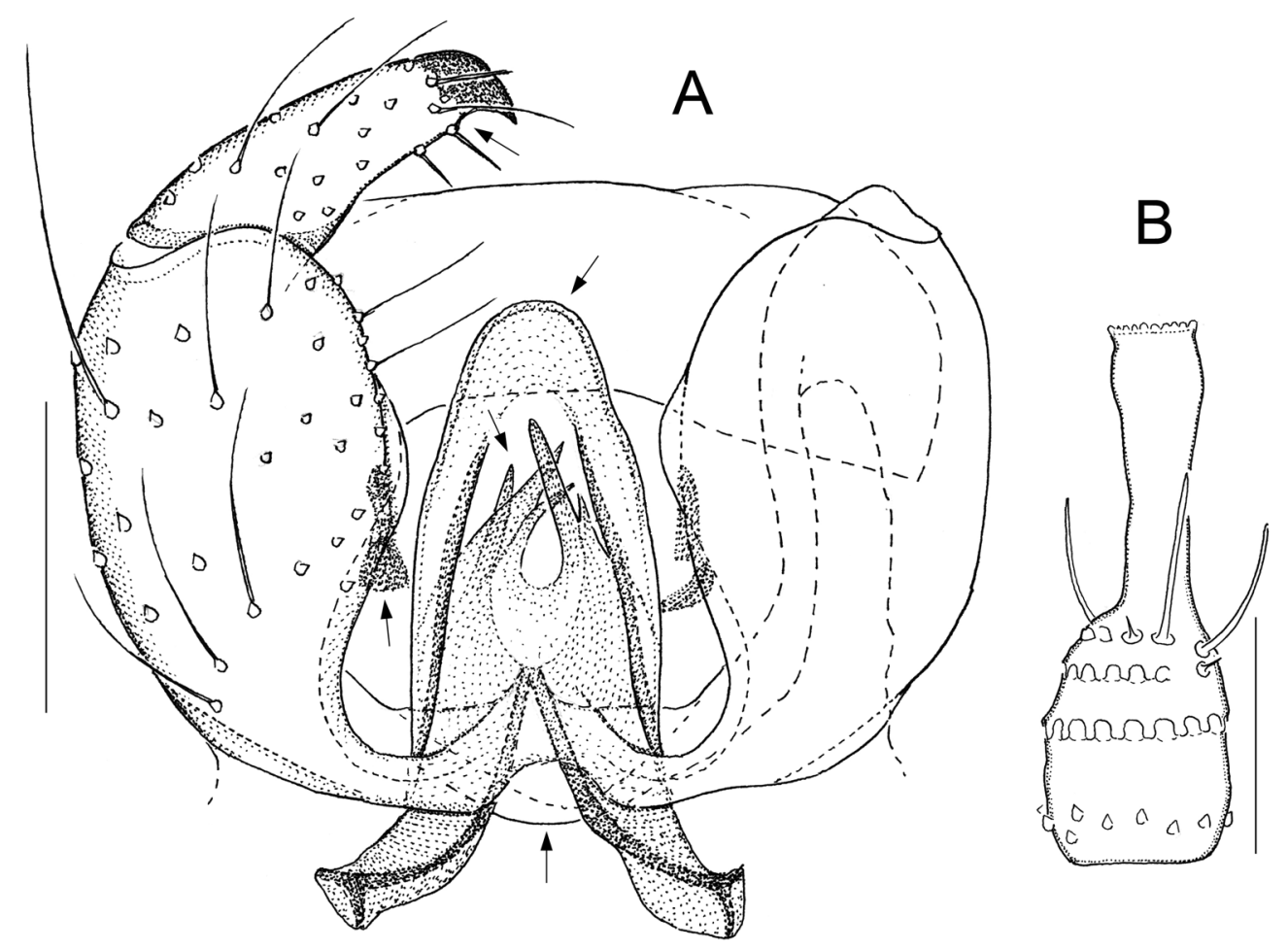

Fig. 12. Aprionus styloideus Mamaev \& Berest, 1990, ô, specimen from Öland (Sweden). A. Genitalia, ventral. B. Fourth flagellomere, lateral. Scale lines: $0.05 \mathrm{~mm}$. Arrows indicate diagnostic characters. 
$16.50^{\circ}$ E, mixed broadleaf forest, MT, MCJ leg., 28 May-27 Jun. 2014 (nos CEC314-CEC319); 1 ○, same data, but 31 Jul.-27 Aug. 2014 (no. CEC320); 1 §̊, Öland, Borgholm, Rönnerum-Abbantorp NR,

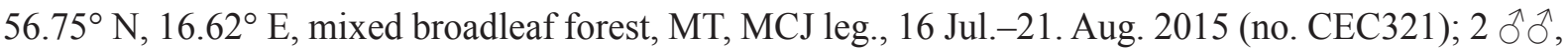
Östergötland, Ödeshög, Omberg, Stocklycke, $58.18^{\circ} \mathrm{N}, 14.37^{\circ} \mathrm{E}$, broadleaf forest, MT, SMTP (trap

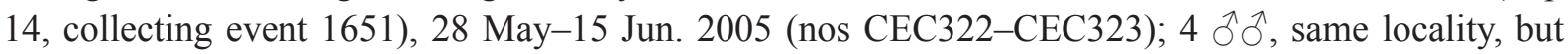
meadow, MT, SMTP (trap 13, collecting event 1647), 2-23 Aug. 2005 (nos CEC324-CEC327).

GERMANY: 4 $\widehat{\partial}$, Mecklenburg-Vorpommern, Karbow, $15 \mathrm{~km}$ SE of Greifswald, swamp forest of alder and ash, ground emergence trap, MJ leg., 2-16 Jun. 1995 (DEI, nos A2322-A2325).

\section{Distribution and phenology}

Sweden (Öland, Östergötland), Germany (Mecklenburg-Vorpommern), Ukraine. Adults were collected from June to August in various broadleaf forests, often with a considerable proportion of ash trees.

\section{Species of the halteratus group unassigned to subgroup}

Gathered here are Aprionus whose male morphology fits the definition of the halteratus group, but does not suggest a closer affinity to any of the subgroups. Besides the new species described below, Aprionus brachypterus and A. fennicus Jaschhof, 2009 are placed here.

Aprionus magnii sp. nov. urn:1sid:zoobank.org:act:D0598010-EC92-4FA2-B5D6-B6E565FD0593

Fig. 13

\section{Diagnosis}

Male genitalic structures of Aprionus magnii sp. nov. (Fig. 13A) are quite distinctive, so that this species can hardly be mistaken for another Aprionus, either of the halteratus or other species group. The gonostylus appears subglobular in ventral view due to its convex, almost swollen basal portion $(\downarrow)$, which transitions into a narrower, dorsally directed portion apically; the small apical tooth $(\downarrow)$ is escorted by 3-4 subapical bristles. Another unique structure is the tegmen, which has only 2 pairs of large, slightly intersecting fingers and a strongly folded apex $(\downarrow)$ separated from the main portion by a constriction $(\downarrow)$.

\section{Etymology}

Magni, one of Thor's two sons and considered the god of might, is believed to be the only being in the Norse universe stronger than his father.

\section{Material examined}

Holotype

SWEDEN: đ, Öland, Mörbylånga, Västerstad elm-forest Nature Reserve, $56.42^{\circ} \mathrm{N}, 16.42^{\circ} \mathrm{E}$, mature elm forest, sweepnet and aspirator, M. and C. Jaschhof leg., 9 Jun. 2014 (NHRS, no. CEC175).

\section{Paratypes}

SWEDEN: $1 \hat{\jmath}$, same data as for the holotype (DEI, no. CEC176); 1 , same locality data, MT, MCJ leg. and SMTP (trap 3002, collecting event 3055), 10 Jul.-5 Aug. 2014 (NHRS, no. CEC177).

\section{Other characters}

Body size $1.1 \mathrm{~mm}$. 
HEAD. Postfrons setose. Eye bridge 2-3 ommatidia long dorsally. A dense row of 9 postocular bristles. Neck of fourth flagellomere shorter than node, 3-4 thick, simply hair-shaped translucent sensilla (Fig. 13B). Palpus 4-segmented, length of segments variable.

WING. ApicR 1 2.5-3.0 times as long as Rs.

LEGs. Claws subrectangular, 1-2 fine teeth. Empodia rudimentary.

TERMinAlia (Fig. 13A). Ninth tergite subrectangular, posterior margin concave, anterior margin almost straight, fully sclerotized. Gonocoxites clearly pointed ventroposteriorly; dorsal bridge extends far anteriorly, subtrapezoid. Subanal plate subrectangular, posterior margin reinforced, darkly marked, with short processes laterally, indistinct, variable dark markings elsewhere.

\section{Distribution and phenology}

Sweden (Öland). The three male specimens known of this species were collected in June-August in a tall broadleaf forest predominated by elm trees.

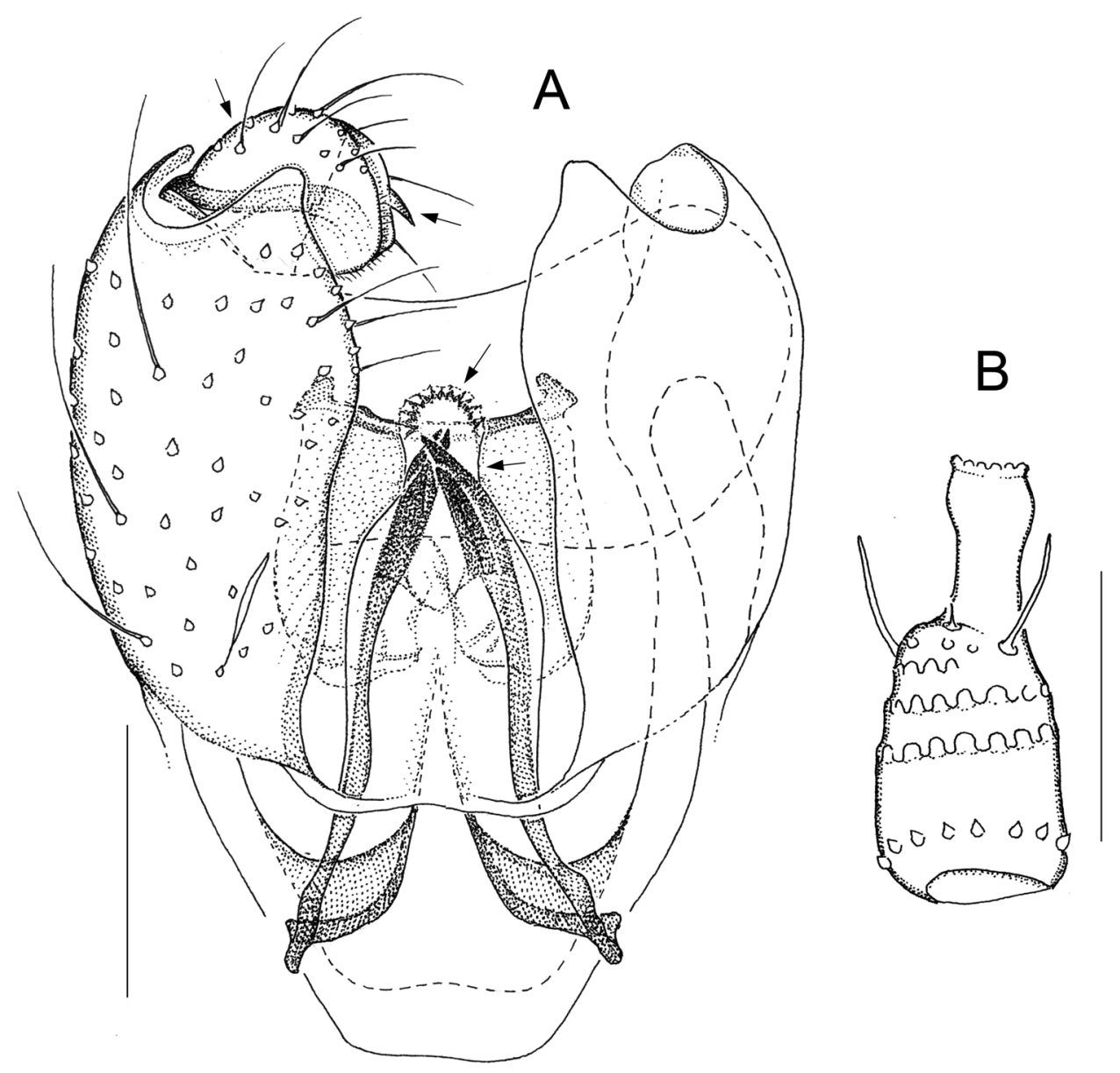

Fig. 13. Aprionus magnii sp. nov., holotype, $\widehat{\jmath}$. A. Genitalia, ventral. B. Fourth flagellomere, lateral. Scale lines: $0.05 \mathrm{~mm}$. Arrows indicate diagnostic characters. 


\section{The smirnovi group}

Named after Aprionus smirnovi Mamaev, 1961, this large group gathers Aprionus whose tegmina lack finger-like processes, a character found also here and there in other groups. The tooth on the gonostylar apex may be present or absent, a distinction that does not suggest any monophyletic subgroups, though. As discussed above, the smirnovi group is unlikely monophyletic but maintained to aid organizing the wealth of morphological structure within Aprionus.

Aprionus fontanus sp. nov.

urn:Isid:zoobank.org:act:0742E67D-D01A-433D-A76E-98ABBB654340

Fig. 14

\section{Diagnosis}

A combination of male genitalic characters is diagnostic of Aprionus fontanus sp. nov., as follows (Fig. 14A). The long tegmen is sharply pointed apically $(\downarrow)$, undoubtedly a firm shape considering that the margins are reinforced. The apical portion of the gonostylus is strongly bent dorsally to dorsolaterally $(\downarrow)$; the gonostylar tooth is flattened; 2 strong bristles are inserted medially. The subrectangular ventral plate has a characteristic pattern of dark markings, including an inverted V-shape medially on the anterior edge.

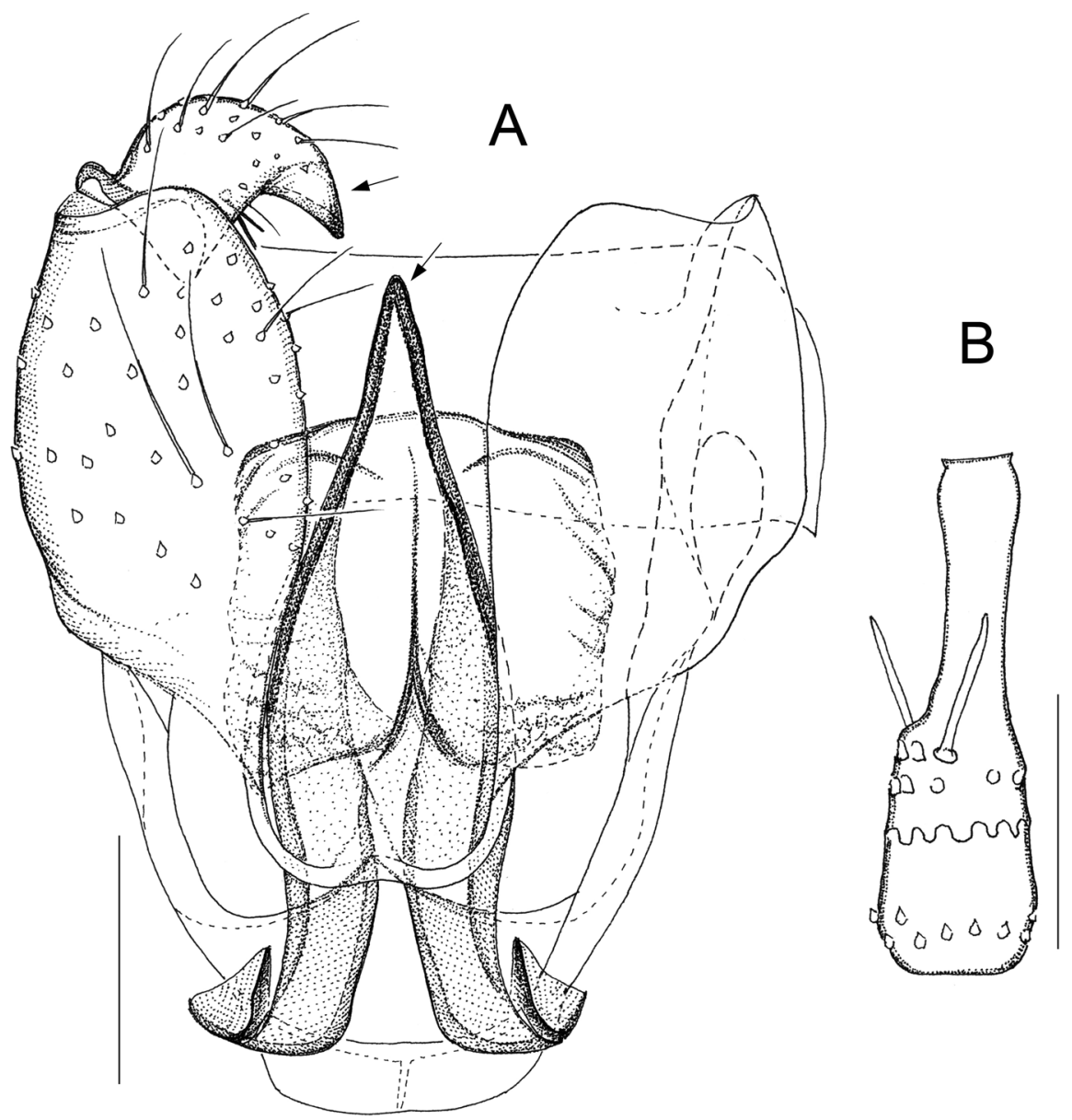

Fig. 14. Aprionus fontanus sp. nov., holotype, ${ }^{\lambda}$. A. Genitalia, ventral. B. Fourth flagellomere, lateral. Scale lines: $0.05 \mathrm{~mm}$. Arrows indicate diagnostic characters. 


\section{Etymology}

The species epithet, fontanus, is a Latin adjective meaning 'belonging to the spring'.

\section{Material examined}

\section{Holotype}

GERMANY: $\widehat{\partial}$, Bavaria, Berchtesgaden National Park, Schapbach alp, Schapbach, $1150 \mathrm{~m}$ a.s.l., emergence trap, I. Schrankel leg., 21 Jun. 1996 (DEI, no. A7655).

\section{Differential diagnosis}

Aprionus angeloides Jaschhof, 1997, a species known from Swedish Lapland, bears a faint resemblance to A. fontanus sp. nov., in particular regarding the outline of the gonostylus and tegmen (see Jaschhof 1998: fig. 148).

\section{Other characters}

Body size $1.2 \mathrm{~mm}$.

HEAD. Postfrons setose. Eye bridge 2-3 ommatidia long dorsally. A sparse row of 7 postocular bristles. Neck of fourth flagellomere slightly longer than node, translucent sensilla simply hair-shaped (Fig. 14B). Palpus 3-segmented, apical segment longest of all.

WING. ApicR 13.0 times as long as Rs.

LEGs. Claws subrectangular, toothless. Empodia rudimentary.

Terminalia (Fig. 14A). Ninth tergite subrectangular, anterior margin fully sclerotized. Gonocoxites rounded rather than pointed ventroposteriorly; dorsal bridge extends far anteriorly, subtrapezoid.

\section{Distribution and phenology}

Germany (Bayern). This species is known from a single specimen found in the course of an inventory of springs and spring biota in the Berchtesgaden National Park (see http://alpenquellen.com/projektgebiet_ berchtesgaden.htm, accessed 26 Nov. 2016).

$$
\begin{aligned}
& \text { Aprionus surtri sp. nov. } \\
& \text { urn:1sid:zoobank.org:act:55935E69-BFB9-422F-A794-4A7BD72C84FD }
\end{aligned}
$$

Fig. 15

\section{Diagnosis}

Aprionus surtri sp. nov. is another distinctive member of the smirnovi group, distinguished by male genitalic characters, as follows (Fig. 15A). The gonocoxites, including their dorsal apodemes, are unusually short; the gonostyli are big $(\downarrow)$ in relation to the gonocoxites; and the tegmen is short and wide - altogether this results in a massive appearance of the terminalia. The dorsal wall of the tegmen is sclerotized and has a V-shaped slit along the longitudinal axis $(\downarrow)$. This structure should not be confused with the ventral plate, which is situated more dorsally and mainly apparent by two small, dot-like sclerotizations at the anterior corners.

\section{Etymology}

Surtr, whose feature is a sword made entirely of fire, is the leader of the fire giants. 


\section{Material examined}

Holotype

SWEDEN: Ô, Öland, Borgholm, Skepparsäng Nature Reserve, $57.31^{\circ} \mathrm{N}, 17.04^{\circ} \mathrm{E}$, mixed coniferous / broadleaf forest, Malaise trap, M. and C. Jaschhof leg., 11 May-10 Jun. 2015 (NHRS, no. CEC191).

\section{Paratype}

SWEDEN: ${ }^{\top}$, Öland, Mörbylånga, Färjestaden, $56.63^{\circ} \mathrm{N}, 16.47^{\circ} \mathrm{E}$, backyard with shrub and young birch trees, MT, MCJ leg., 19 Aug.-6 Oct. 2015 (DEI, no. CEC303).

\section{Other characters}

Body size $1.9 \mathrm{~mm}$.

HEAD. Postfrons setose. Eye bridge 3-4 ommatidia long dorsally. A rather sparse row of 8-9 postocular bristles. Flagellomeres with up to 3 complete crenulate whorls. Neck and node of fourth flagellomere almost same length, both hair-shaped and branched translucent sensilla ( $\downarrow$, Fig. 15B). Palpus long, 3 -segmented, apical segment very long, clearly the result of two segments merged into one.

WING. ApicR 13.5 times as long as Rs.

LEGS. Claws subrectangular, 2-3 teeth. Empodia rudimentary.

Terminalia (Fig. 15A). Ninth tergite subrectangular, anterior margin only laterally sclerotized. Gonocoxites rounded ventroposteriorly; dorsal apodemes and bridge short, not extending beyond anterior gonocoxal edge. Gonostylus elongate, slightly bent, evenly tapered towards apex; apical tooth small, 2-3 inconspicuous bristles subapically. Tegmen twice as long as wide, parallel-sided on basal

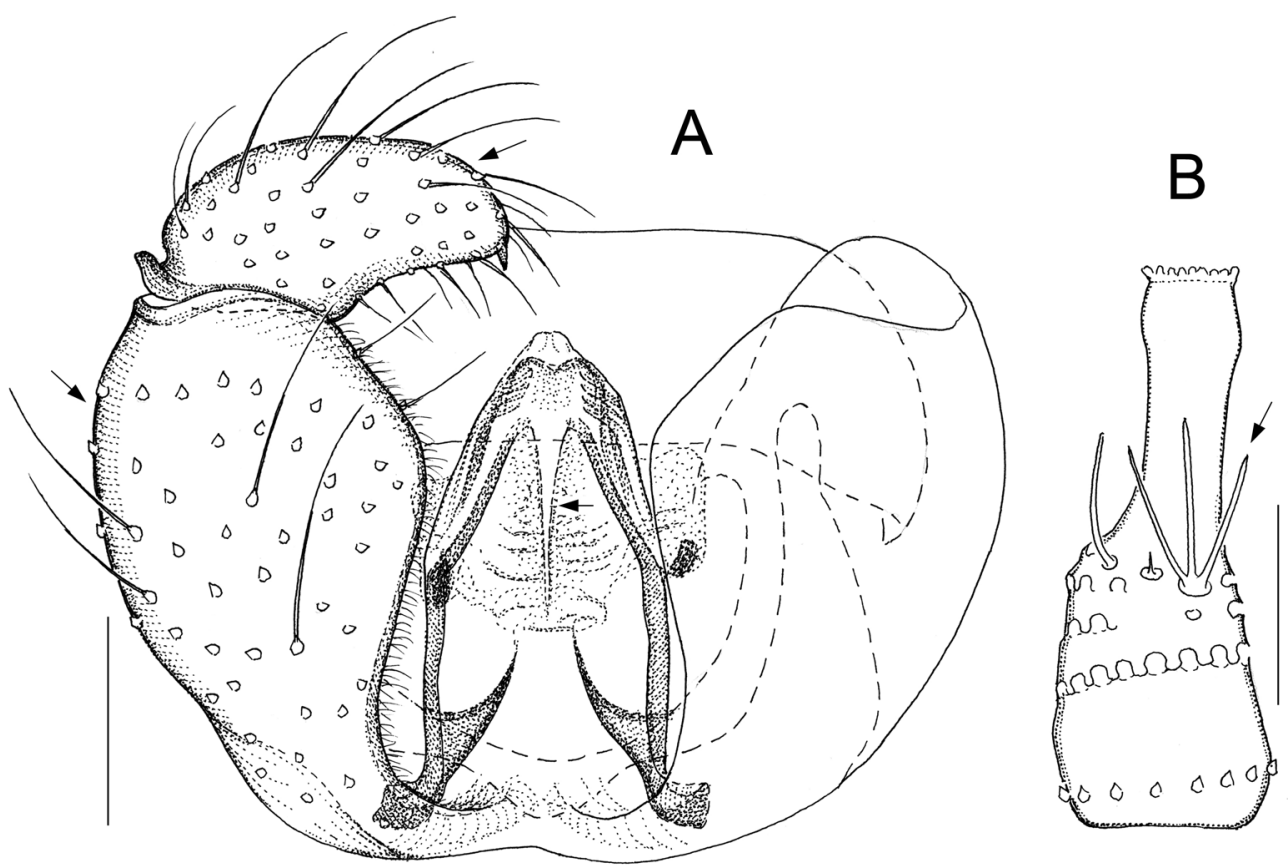

Fig. 15. Aprionus surtri sp. nov., holotype, $\widehat{\jmath}$. A. Genitalia, ventral. B. Third flagellomere, lateral. Scale lines: $0.05 \mathrm{~mm}$. Arrows indicate diagnostic characters. 
half, then tapered to tip; with fold-like structuring subapically, possibly indicating rudimentary fingers. Subanal plate inconspicuous, membranous rather than sclerotized.

\title{
Distribution and phenology
}

Sweden (Öland). The two specimens known of this species were collected in late spring and early autumn in habitats as different as dense forest and open grove.

\author{
Aprionus tyri sp. nov. \\ urn:1sid:zoobank.org:act:1157FB7B-98F0-4060-8260-9F4CE291B881
}

Fig. 16

\section{Diagnosis}

Aprionus tyri sp. nov. is extremely similar to A. magnussoni Jaschhof \& Jaschhof, 2015. The most obvious distinction is the shape of the gonostylus, which in $A$. tyri sp. nov. is essentially elongate, i.e., three times as long as wide, with the posterior margin slightly convex ( $\downarrow$, Fig. 16A) and in A. magnussoni is compact, i.e., two times as long as wide, with the posterior margin strongly convex (Jaschhof \& Jaschhof 2015: fig. 3A ). Another distinction, but one that is hard to depict because the relevant structures are tiny, is the gonostylar tooth, which is rather straight and with the base broadly adpressed to the gonostylar body in A. tyri sp. nov., while beak-shaped and protruding from the gonostylar body in A. magnussoni. The tegmen of $A$. tyri sp. nov. is slightly bulkier and has a pair of dark (refractive) margins ventrally ( $\downarrow$, Fig. 16A); these are absent in A. magnussoni (Jaschhof \& Jaschhof 2015: fig. 3A). The subanal
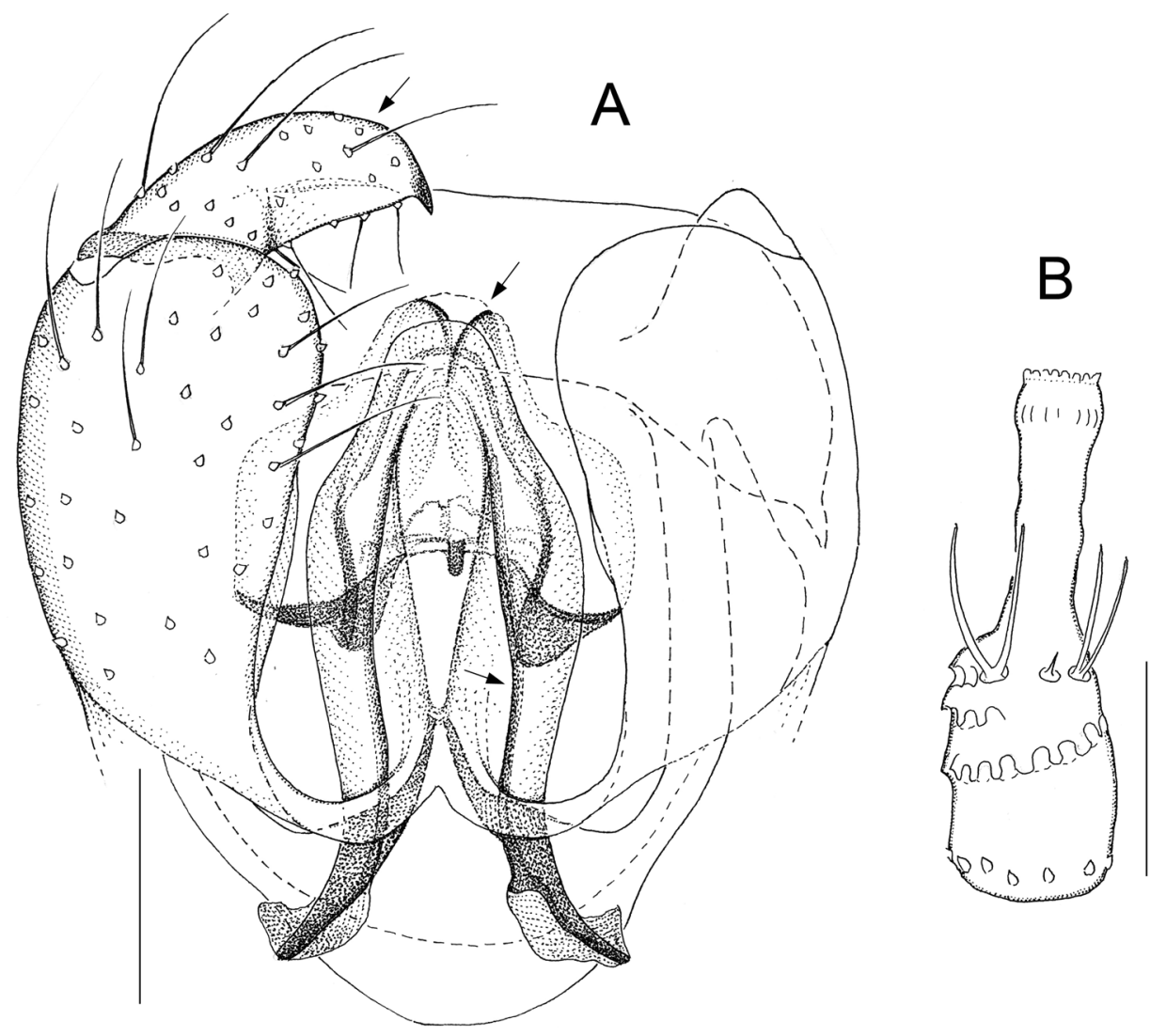

Fig. 16. Aprionus tyri sp. nov., holotype, ${ }^{\jmath}$. A. Genitalia, ventral. B. Fourth flagellomere, lateral. Scale lines: $0.05 \mathrm{~mm}$. Arrows indicate diagnostic characters. 
plate of $A$. tyri sp. nov. is broader and has a narrow, $\mathrm{V}$-shaped sclerotization on the posterior margin $(\downarrow$, Fig. 16A); in A. magnussoni this margin is broadly U-shaped (Jaschhof \& Jaschhof 2015: fig. 3A). Nongenitalic morphology (see Jaschhof \& Jaschhof 2015: 164) is identical in both species.

\section{Etymology}

Tyr, whose one-handedness is an important defining attribute, is regarded as one of the principal war gods.

\section{Material examined}

\section{Holotype}

SWEDEN: O, Halland, Laholm, Mästocka heathland, $56.36^{\circ} \mathrm{N}, 13.14^{\circ} \mathrm{E}$, heath near grove, Malaise trap, Swedish Malaise Trap Project (trap 34, collecting event 1091), 4-15 Jun. 2004 (NHRS, no. CEC180).

\section{Paratypes}

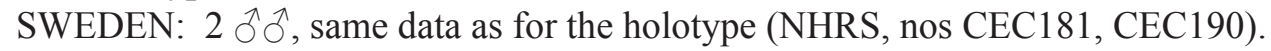

\section{Other material studied}

SWEDEN: 1 ภ, Öland, Mörbylånga, Ottenby, Södra lunden, $56.13^{\circ} \mathrm{N}, 16.25^{\circ} \mathrm{E}$, nemoral grove, MT,

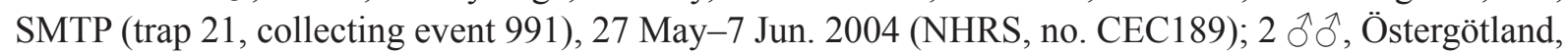
Ödeshög, Omberg, Stocklycke meadow, $58.18^{\circ} \mathrm{N}, 14.37^{\circ} \mathrm{E}$, calcareous meadow, MT, SMTP (trap 13, collecting event 909), 25 May-8 Jun. 2003 (NHRS, nos CEC187-188); 5 $\widehat{\jmath}$, Lule Lappmark, Jokkmokk, Norden, Sikan river, swampy birch forest, MT, MCJ leg., 12 Jul.-9 Aug. 2005 (DEI, nos CEC182-186).

\section{Remarks}

Specimens described here as $A$. tyri sp. nov. were first thought to be atypical A. magnussoni, until we discovered that both morphotypes occur sympatrically (even in one and the same Malaise sample) without showing intermediate characters. Our decision to consider these two morphotypes to be distinct species is based on the study of 11 males of $A$. tyri sp. nov. from four different localities, and 10 males of $A$. magnussoni from two different localities. Sympatric occurrence was observed at the type-locality.

\section{Specimens of Aprionus magnussoni studied}

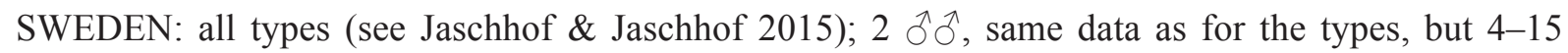
Jun. 2004 (DEI, nos CEC125-126); 1 ðิ, Öland, Mörbylånga, Frösslunda alvar, 56.32 ${ }^{\circ} \mathrm{N}, 16.34^{\circ} \mathrm{E}$, alvar pasture, MT, SMTP (trap 20, collecting event 1495), 9 May-3 Jun. 2005 (NHRS, no. CEC124).

\section{Distribution and phenology}

Sweden (Halland, Öland, Östergötland, Lule Lappmark). This species was found to occur in various types of open woodland and scrubby grassland from the nemoral to the boreal zones, with adults collected in late spring (in the south) and summer (in the north).

Aprionus ymiri sp. nov. urn:1sid:zoobank.org:act:1DF5CB60-323F-4323-8193-E7A68862BDCB

Fig. 17

\section{Diagnosis}

The male genitalic structures of Aprionus ymiri sp. nov. are as simple as characteristic of this species. The gonostylus is composed of two portions of the same size, a slightly convex portion basally and a flat 
portion apically; the gonostylar apex is narrowly rounded and provided with ordinary setae and setulae, no teeth or bristles ( $\downarrow$, Fig. 17B). The tegmen, which is tapered from the midlength to the narrowly rounded apex, is provided with 2 pairs of small, weakly contoured fingers, which do not intersect medially due to their rearward orientation ( $\downarrow$, Fig. 17A). A ventral plate is not apparent in this species.

\section{Etymology}

Ymir is the ancestor of all jotunn, a mythological race commonly glossed as the giants.

\section{Material examined}

\section{Holotype}

SWEDEN: đ̂, Öland, Borgholm, Skepparsäng Nature Reserve, $57.31^{\circ} \mathrm{N}, 17.04^{\circ} \mathrm{E}$, dry pine forest, Malaise trap, M. and C. Jaschhof leg., 11 Jun.-21 Jul. 2015 (NHRS, no. CEC288).

\section{Paratype}

FINLAND: $\widehat{0}$, Karelia borealis, Lieksa, Patvinsuo NP, $63.08^{\circ} \mathrm{N}, 30.37^{\circ} \mathrm{E}$, mature spruce forest with birch and aspen trees, MT, MCJ leg., 12 Jun.-7 Jul. 2004 (DEI, no. CEC289).

\section{Differential diagnosis}

Aprionus ymiri sp. nov. lacks characters that, seen individually, would catch the observer's attention, but the combination of characters as described above is species-specific. To avoid misidentification, this rarely found species should be compared with both Aprionus dispar Mamaev, 1963 and A. pseudispar Jaschhof, 1997 (see Jaschhof 1998: figs 151, 155), two much more common species.
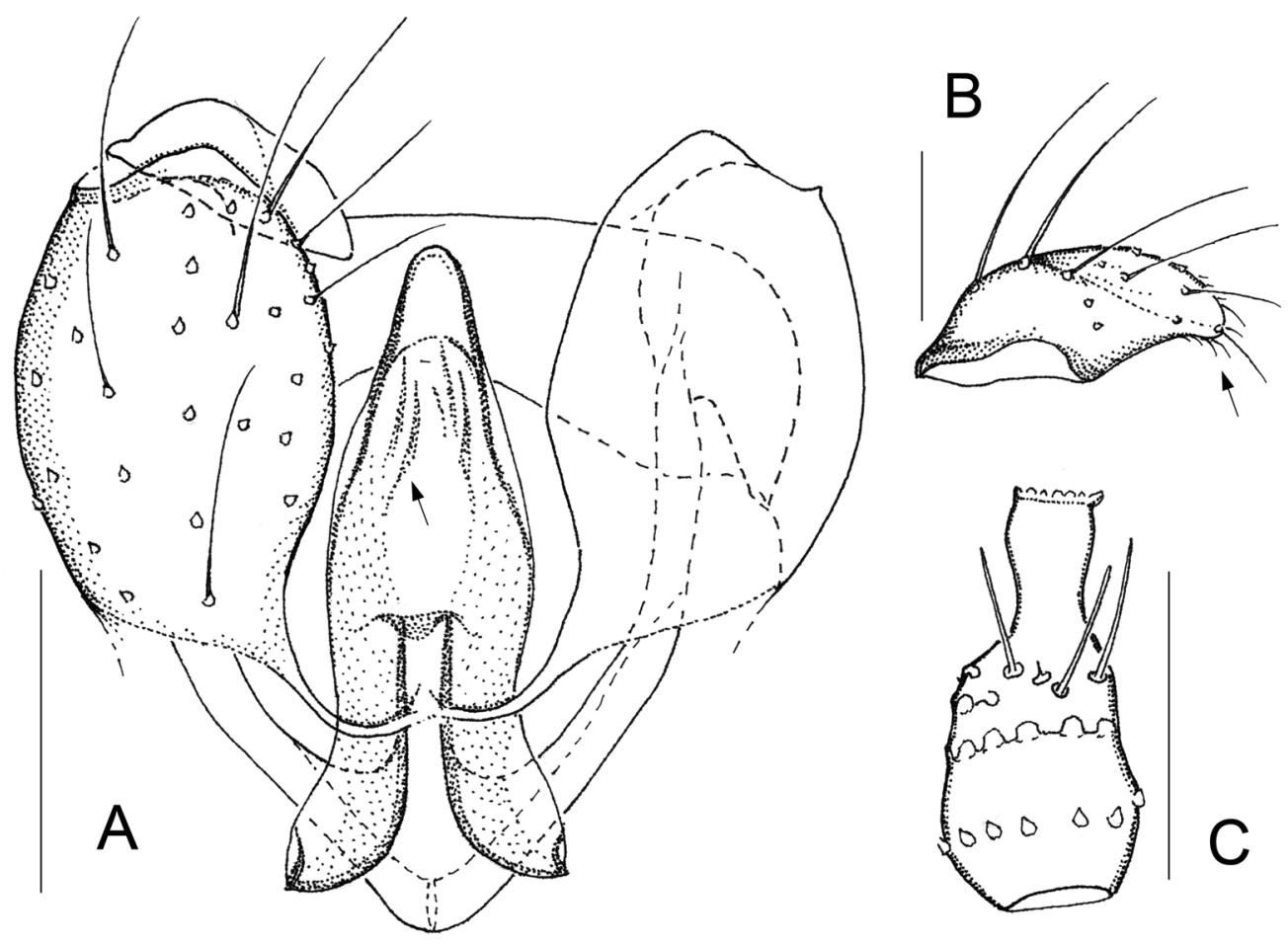

Fig. 17. Aprionus ymiri sp. nov., đ. A. Genitalia, ventral, holotype. B. Gonostylus, ventral, paratype. C. Fourth flagellomere, lateral, paratype. Scale lines: A, C $=0.05 \mathrm{~mm} ; \mathrm{B}=0.025 \mathrm{~mm}$. Arrows indicate diagnostic characters. 


\section{Other characters}

Body size $1.1 \mathrm{~mm}$.

HeAd. Postfrons setose. Eye bridge 2-3 ommatidia long dorsally. Postocular bristles: 10 in holotype, 7 in paratype. Neck of fourth flagellomere shorter than node, thick, simply hair-shaped translucent sensilla (Fig. 17C). Palpus short, 3-segmented in holotype, 2-segmented (but equally long) in paratype, basal segment somewhat swollen.

WING. ApicR 1 2.5-3.0 times as long as Rs.

LEGs. Claws sickle-shaped, toothless. Empodia rudimentary.

TERMinAlia (Fig. 17A). Ninth tergite subrectangular, anterior margin fully sclerotized, concave medially. Gonocoxites slightly pointed ventroposteriorly, dorsal bridge small, subtriangular, extends far beyond ventroanterior gonocoxal margin.

\section{Distribution and phenology}

Sweden (Öland), Finland (Karelia borealis). Adults were collected in June-July in various types of forest.

\section{Aprionus incertae sedis}

This category gathers Aprionus, 12 described in the past and three described here, that cannot be classified in any of the species groups recognized so far (Jaschhof 1998; Jaschhof \& Jaschhof 2009). We think that the number of 'unplaceables' will not increase with more species being found and described in the future; rather we expect that the affinities of these species to other Aprionus will be illuminated and the intrageneric structure of Aprionus improved with ongoing study (see the differential diagnoses of Aprionus bestlae sp. nov. and $A$. borri sp. nov.).

\section{Aprionus bestlae sp. nov. urn:1sid:zoobank.org:act:B5DD5BA9-4FE0-4C4C-BF5B-8B7DCE37E7F6}

Fig. 18

\section{Diagnosis}

A combination of male genitalic characters distinguishes Aprionus bestlae sp. nov., as follows (Fig. 18A). The elongate, subcylindrical gonostylus lacks an apical tooth $(\downarrow)$; the long tegmen is provided with 3-5 pairs of large, intertwining fingers; and the subanal plate has conspicuous dark markings at the anterior edge, an inverted $\mathrm{V}$-shape medially and markings of varying shape and extent laterally $(\downarrow)$.

\section{Etymology}

Bestla, daughter of the giant Bölthorn, is Odin's mother.

\section{Material examined}

\section{Holotype}

SWEDEN: ${ }^{\top}$, Öland, Mörbylånga, Gamla Skogsby, $56.37^{\circ} \mathrm{N}, 16.30^{\circ} \mathrm{E}$, scrubby meadow at forest edge ('diversity meadow'), Malaise trap, M. and C. Jaschhof leg., 30 Apr.-8 Jun. 2015 (NHRS, no. CEC192).

\section{Paratypes}

SWEDEN: 2 ðð, Öland, Borgholm, Lindreservat NR, $57.31^{\circ} \mathrm{N}, 17.04^{\circ} \mathrm{E}$, mixed broadleaf forest, MT, MCJ leg., 11 Jun.-21 Jul. 2015 (1 paratype each in NHRS and DEI, nos CEC304-CEC305). 


\section{Other material studied}

CZECH REPUBLIC: 1 §ิ, Moravia, White Carpathians, Klabenka, MT, J. Ježek leg., 3 Jun. 2008 (TSPC, no. CEC306).

\section{Differential diagnosis}

Three other Aprionus incertae sedis, Aprionus dentifer Mamaev, 1965 (see Jaschhof 1998: fig. 180), A. pyxidiifer Mamaev, 1998 (see Jaschhof \& Jaschhof 2009: fig. 103), and A. svecicus Jaschhof, 1996, are generally similar to $A$. bestlae sp. nov., especially with respect to the gonostylus, tegmen and subanal plate. Also, the antennae of all four species have branched translucent sensilla. These similarities can hardly lead to misidentification, as each of the species is sufficiently distinct, rather they might indicate common ancestry. Study of Aprionus in the future will reveal whether it is justified to refer to the species in question as the dentifer group.

\section{Other characters}

Body size $1.8 \mathrm{~mm}$.

HEAD. Postfrons setose. Eye bridge 3 ommatidia long dorsally. A dense row of 9-10 postocular bristles. Neck of fourth flagellomere as long as node, or slightly longer; translucent sensilla both hair-shaped and variously branched (Fig. 18B). Palpus long, with 3-4 segments, if 3-segmented, then apical segment very long and/or clearly consisting of two merged segments.

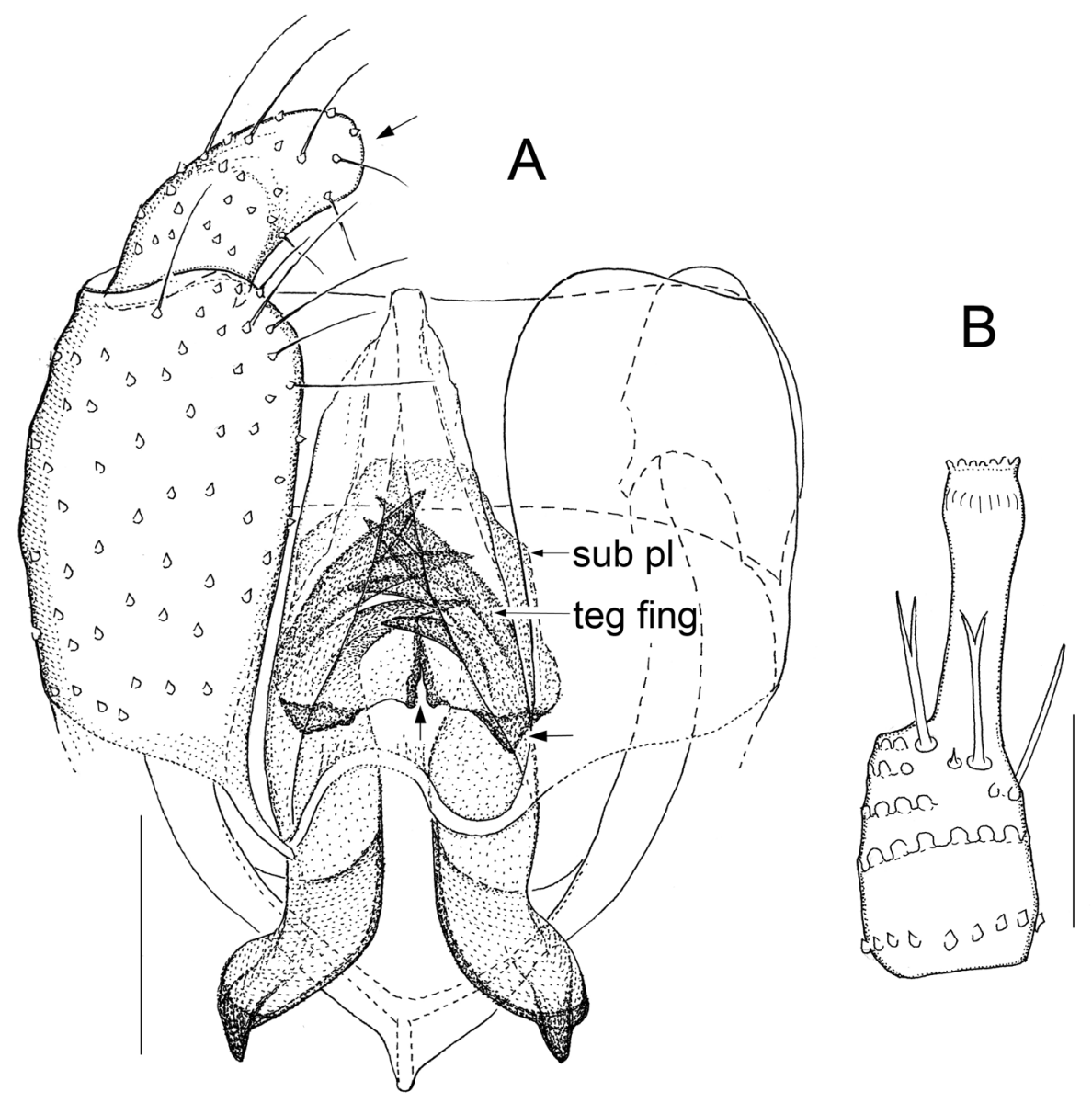

Fig. 18. Aprionus bestlae sp. nov., holotype, §̊. A. Genitalia, ventral. B. Fourth flagellomere, lateral. Scale lines: $0.05 \mathrm{~mm}$. Arrows indicate diagnostic characters. 
WING. ApicR $13.5-4.0$ times as long as Rs.

LEgs. Claws subrectangular, 3 teeth. Empodia rudimentary.

Terminalia (Fig. 18A). Ninth tergite subrectangular, anterior margin fully sclerotized. Gonocoxites rounded ventroposteriorly; ventral bridge forms stable loop medially; dorsal bridge subtriangular, extends far beyond ventroanterior margin. Gonostylus with slightly convex basal portion, somewhat flattened apical portion, apex broadly rounded, up to 4 subapical bristles. Apical portion of tegmen membranous, therefore of varying outline. Posterior portion of subanal plate lacks clear contours.

\section{Distribution and phenology}

Sweden (Öland), Czech Republic. The few specimens known of Aprionus bestlae sp. nov. were collected in late spring/early summer in both forest and meadow next to forest.

Aprionus borri sp. nov. urn:1sid:zoobank.org:act:F17CA9EB-9D1F-47A1-9861-FC7054FAA837

Fig. 19

\section{Diagnosis}

Among Aprionus with toothed gonostyli, Aprionus borri sp. nov. is the only species whose tegminal fingers are reduced to a single pair that forms the lateral and apical margins of the tegmen ( $\downarrow$, Fig. 19A).

\section{Etymology}

Borr, husband of Bestla, is Odin's father.

\section{Material examined}

\section{Holotype}

SWEDEN: ${ }^{\top}$, Öland, Mörbylånga, Gamla Skogsby, $56.61^{\circ} \mathrm{N}, 16.51^{\circ} \mathrm{E}$, mixed broadleaf forest, Malaise trap, M. and C. Jaschhof leg., 27 Jun.-30 Jul. 2014 (NHRS, no. CEC159).

\section{Paratypes}

SWEDEN (4 paratypes in NHRS, 5 in DEI): 1 $\hat{~}$, same data as the holotype (no. CEC160); 1 , same data, but 9 Jun.-14 Jul. 2015 (no. CEC308); 1 đ, same data, but 15 Jul.-17 Aug. 2015 (no. CEC167); 1 đ̊, Öland, Mörbylånga, Stora Dalby forest NR, $56.47^{\circ} \mathrm{N}, 16.45^{\circ} \mathrm{E}$, mixed broadleaf forest with much

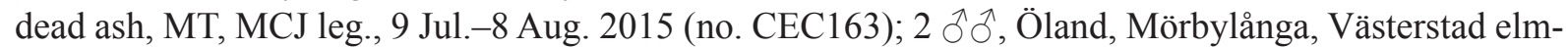
forest NR, $56.42^{\circ} \mathrm{N}, 16.42^{\circ} \mathrm{E}$, mature elm forest, MT, MCJ leg. with the SMTP (trap 3002, collecting event 3055), 10 Jul.-5 Aug. 2014 (nos CEC161-CEC162); 1 ô, Öland, Borgholm, Lindreservat NR, $57.31^{\circ} \mathrm{N}, 17.04^{\circ} \mathrm{E}$, mixed deciduous forest, MT, MCJ leg., 11 Jun.-21 Jul. 2015 (no. CEC307); 1 ○, Öland Borgholm, Horns kungsgård NR, $57.20^{\circ} \mathrm{N}, 16.93^{\circ} \mathrm{E}$, mixed forest of birch, alder and willow trees at lakeside, MT, MCJ leg., 21 Jul.-22 Aug. 2015 (no. CEC168); 1 ○ૈ, Öland, Borgholm, Skepparsäng $\mathrm{NR}, 57.31^{\circ} \mathrm{N}, 17.04^{\circ} \mathrm{E}$, mixed coniferous/broadleaf forest, MT, MCJ leg., 11 Jun.-21 Jul. 2015 (no. CEC166).

\section{Differential diagnosis}

At a cursory glance, the tegmen of Aprionus borri sp. nov. seems to lack finger-like processes, especially in those slide-mounts where the finger apices intersect and then appear like they would form a closed, rounded margin apically. Aprionus with apically entire, fingerless tegmina (and toothed gonostyli) are A. ferulae Mamaev, 1998, a little-known species from Turkmenistan; A. reduncus Jaschhof, 2009, a species rarely collected in Fennoscandia; and A. umbrellus Mamaev \& Berest, 1990, found once 
in Ukraine. The presence of a single, marginalized pair of tegminal fingers is not only a character to distinguish $A$. borri sp. nov. from these other species; more interesting is our observation that exactly the same type of tegmen (in combination with toothed gonostyli) occurs in several unnamed species in our collection from Japan, Malaysia, and South Africa. All these species are so similar to each other, also in other respects, that one can hardly question their close interrelationship. It appears that $A$. borri sp. nov. is an (or the) European representative of a species group, potentially the borri group, with a wide distribution in the Old World. (For the sake of completeness it is mentioned here that there are also Aprionus, in which the presence of an apically entire, fingerless tegmen is combined with untoothed gonostyli, namely A. carpathicus Mamaev \& Berest, 1992 (Ukraine), A. dispar Mamaev, 1963 (widespread Europe), and A. pseudispar Jaschhof, 1997 (Sweden, Germany).)

\section{Other characters}

Body size $1.0 \mathrm{~mm}$.

HeAd. Postfrons setose. Eye bridge 1-2 ommatidia long dorsally. A dense row of 8-10 postocular bristles. Flagellomeres usually 12, in one of the specimens studied 11 due to fusion of the two apical flagellomeres. Fourth flagellomere with neck much shorter than node, 1 complete and 2 incomplete crenulate whorls, simply hair-shaped translucent sensilla (Fig. 19B). Presence of translucent sensilla confined to 5 proximal flagellomeres. Palpus short, 3-segmented, basal segment slightly swollen, apical segment pointed, longest of all.

WING. ApicR $1.5-2.0$ times as long as Rs.

LEGS. Claws subrectangular, toothless. Empodia rudimentary.

TERMinAlia (Fig. 19A). Ninth tergite much shorter medially than laterally, anterior margin not sclerotized. Gonocoxites: ventral bridge fully membranous, indistinct; dorsal apodemes short, ending well before ventroanterior gonocoxal margin, dorsal bridge broadly rounded. Gonostylus slender, evenly tapered

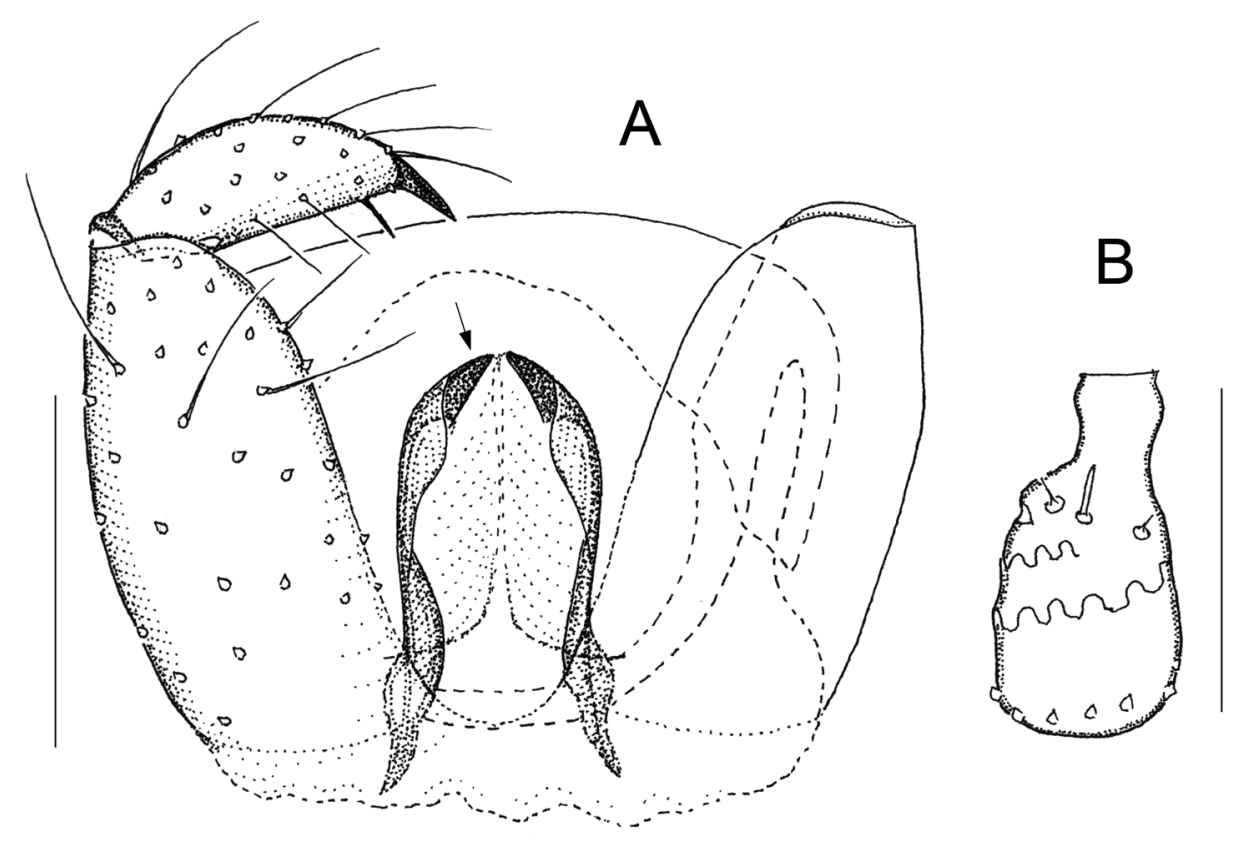

Fig. 19. Aprionus borri sp. nov., holotype, $\widehat{\partial}$. A. Genitalia, ventral. B. Fourth flagellomere, lateral. Scale lines: $0.05 \mathrm{~mm}$. The arrow indicates an important diagnostic character. 
to tip; apical tooth large, its size relative to gonostylar body varying, appears sharply pointed in lateral view but is actually flattened and rounded apically; $0-1$ bristles subapicomedially. Tegmen twice as long as wide, widest on apical third portion; dorsal wall weakly sclerotized, apparently with slit-like lengthwise opening. Subanal plate without clear contours, recognizable by irregular dark markings ('folds') dorsally of tegmen.

\title{
Distribution and phenology
}

Sweden (Öland). Specimens of Aprionus borri sp. nov. were collected from June to August in various broadleaf forests on the island of Öland.

\author{
Aprionus montivagus sp. nov. \\ urn:lsid:zoobank.org:act:BB33205B-4CFF-410A-9D72-C03E7124023C
}

Fig. 20

\section{Diagnosis}

Aprionus montivagus sp. nov. is another distinctive species whose male genitalic structures provide obvious distinguishing characters (Fig. 20A). The gonostylus, viewed from the ventral side, appears rather slender and subtriangular, but is roundish and strongly flattened in a posterior view (Fig. 20B); the outer surface is covered with setae of different sizes (as in other Aprionus), while the inside is densely microtrichose $(\downarrow)$. The elongate, almost parallel-sided tegmen bears 2-3 pairs of small, thin fingers, which are in a very characteristic way bent dorsally $(\downarrow)$. The broad subanal plate has a straight, strongly sclerotized posterior edge $(\downarrow)$.

\section{Etymology}

The species epithet, montivagus, is a Latin adjective meaning 'roaming the mountains'.

\section{Material examined}

\section{Holotype}

AUSTRIA: $\widehat{\jmath}$, Niederösterreich, Dürrenstein Nature Reserve, Rothwald, Kleiner Urwald, $47.46^{\circ} \mathrm{N}$, $15.07^{\circ} \mathrm{E}, 1035 \mathrm{~m}$ a.s.1., virgin forest of beech, fir and spruce trees, ground emergence trap (no. 11), C. Wurth leg., Aug. 2002 (DEI, no. A7642).

\section{Paratypes}

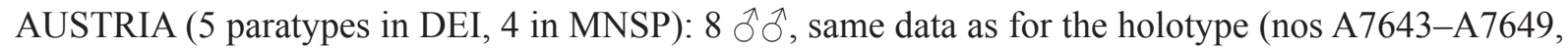
A7651); 1 ${ }^{\lambda}$, same data, but with Barber trap (no. 11) (no. A7650).

\section{Other material studied}

RUSSIA: $3 \hat{\jmath} \widehat{\jmath}$, Krasnodarskiy Kray, Caucasus Mountains, Mount Abago, S Guzeripl, $2200 \mathrm{~m}$ a.s.l., sweepnet, W. Mohrig leg., 29 Jul. 1994 (DEI, nos A7652-A7654).

\section{Other characters}

Body size $1.8 \mathrm{~mm}$.

Head. Postfrons setose. Eye bridge 2-3 ommatidia long dorsally. A row of 7-9 postocular bristles. Neck of fourth flagellomere shorter than node; translucent sensilla hair-shaped (Fig. 20C). Palpus long, 4-segmented.

WING. ApicR 1 3.0-3.5 times as long as Rs. 
Legs. Claws subrectangular, 2 tiny teeth. Empodia rudimentary.

Terminalia (Fig. 20A). Ninth tergite long, subrectangular, anterior margin fully sclerotized. Gonocoxites narrow, rounded ventroposteriorly; dorsal bridge subrectangular, extends far beyond ventroanterior gonocoxal margin. Gonostylus without apical tooth or subapical bristles. Tegmen blunt-ended.

\section{Distribution and phenology}

Austria (Niederösterreich), Russia (Near East). This species is known from two series of specimens collected at the height of summer at higher elevations, one series in the European Alps and the other in the Caucasus Mountains. The type locality, Rothwald, is unanimously described as Austria's most precious primeval forest. Details of the collecting site in the Caucasus are not known.

\section{Discussion}

Until the mid-1990s the subfamily Lestremiinae, where Aprionus was then classified, was known to comprise about 400 species and regarded as containing mostly species-poor genera (Harris 1994). At that time 42 species of Aprionus were scientifically described, 32 of these in the years 1963-1992. Since then Aprionus has been found to be a remarkably speciose genus. Now comprising 131 species, Aprionus is the second largest genus of fungivorous Cecidomyiidae. The fact that 95 (72\%) of these

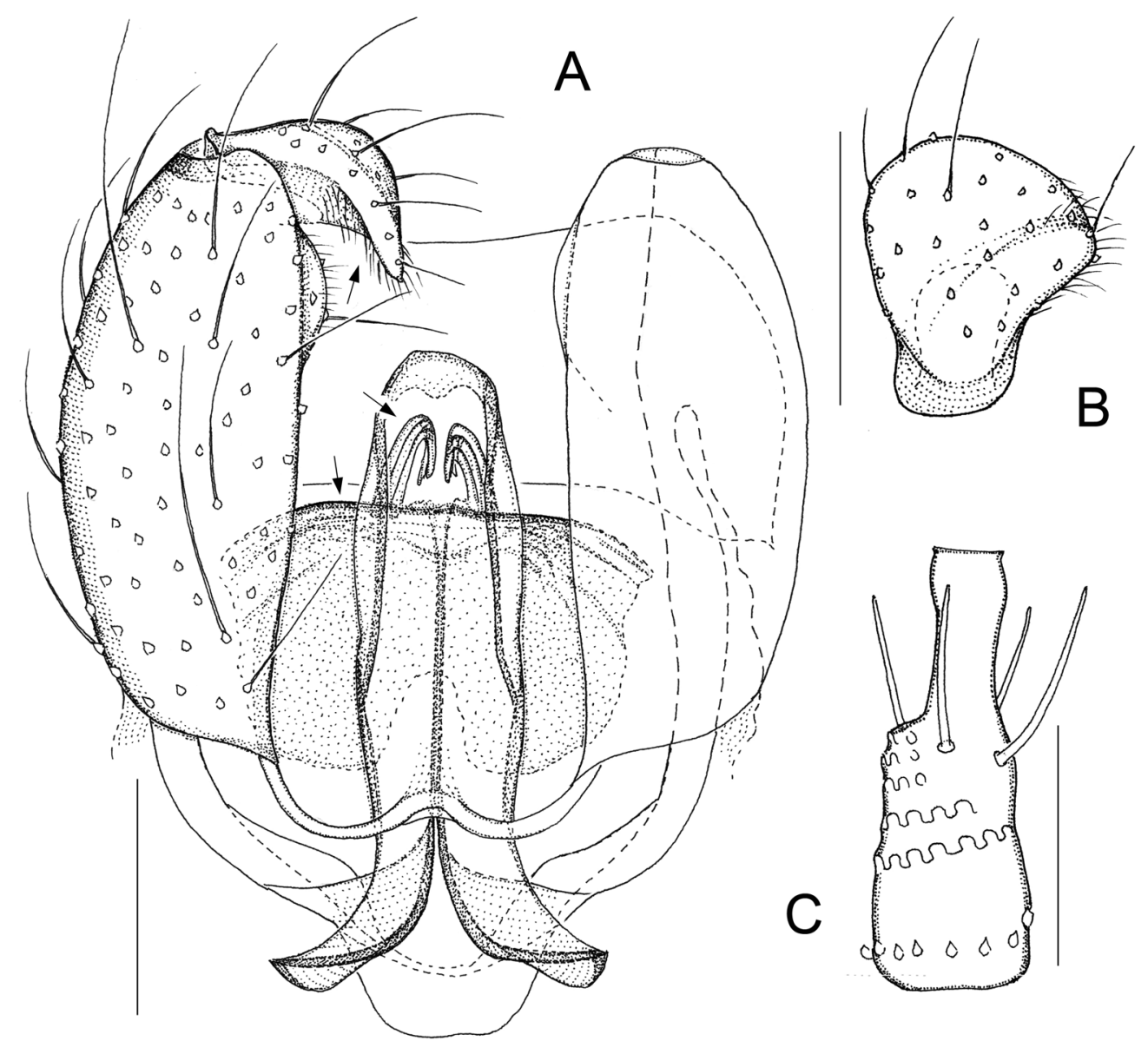

Fig. 20. Aprionus montivagus sp. nov., ふึ. A. Genitalia, ventral, holotype. B. Gonostylus, posterior, paratype. C. Fourth flagellomere, lateral, paratype. Scale lines: $0.05 \mathrm{~mm}$. Arrows indicate diagnostic characters. 
species are now shown to occur in a single country, Sweden, is interesting for several reasons. Most importantly, it proves the potency of well-conceived and well-funded faunistic inventories, which enable taxonomists to conduct research into taxa that are at the same time megadiverse, methodologically demanding, and extremely poorly known due to long neglect in the past. While many funding bodies regard such groups as bottomless pits rather than goldmines of new information, the Swedish Taxonomy Initiative (STI), an effort to identify all the species of multicellular organisms in the country (see http://www.artdatabanken.se/en/the-swedish-taxonomy-initiative/), makes a difference here. Research funded by STI discovered 64 out of 95 Aprionus species in Sweden, of which 34 were described as new to science. Furthermore, the concentration of Aprionus in Sweden should not be interpreted as a biogeographic pattern; it is an artifact of insufficient survey in most other parts of Europe, the Palearctic region, and the world. According to unpublished data at our disposal, the genus Aprionus is cosmopolitan in distribution and apparently so species-rich that its true diversity is impossible to estimate. So little is published of the true diversity of Aprionus that every single description of a new species usually leads to a better understanding of interspecific relationships in this complex genus. The treatment of Aprionus incertae sedis in the present paper shows how new species data help to improve our view of intrageneric relationships. Likewise, developing the generic classification of the Aprionini, the tribe to which Aprionus belongs, will certainly involve extensive descriptive work at the level of species. Our present knowledge of the genus, now based on male morphology and helpful information on geographical distribution, adult habitat and phenology, constitutes a matrix to which will be added pieces of information about females, other stages, and biology as these become known.

\section{Acknowledgements}

This paper is an outcome of the Gall Midge Project funded by Svenska ArtDatabanken (Swedish Species Information Centre) within the framework of Svenska Artprojektet (Swedish Taxonomy Initiative) (dha 2014-150 4.3). Several fellow entomologists provided specimens to study, namely Dieter Doczkal, Kaoru Maeto, Werner Mohrig, Erik Rindal, Björn Rulik, Isabel Schrankel, and Claudia Wurth. Stephan Blank suggested naming new species after figures from Norse mythology. Raymond J. Gagné was so kind to read the manuscript before submission to the journal. Comments by two reviewers and work by the editorial team helped to improve considerably the readability of this paper.

\section{References}

Gagné R.J. \& Jaschhof M. 2014. A Catalog of the Cecidomyiidae (Diptera) of the World. 3rd Edition. Digital version 2. Available from http://www.ars.usda.gov/SP2UserFiles/Place/12454900/Gagne_2014_ World_Cecidomyiidae_Catalog_3rd_Edition.pdf [accessed 26 Nov. 2016].

Harris K.M. 1994. 12. Gall midges (Cecidomyiidae): classification and biology. In: Williams M.A.J. (ed.) Plant Galls: 201-211. Systematics Association Special Volume 49, Clarendon Press, Oxford.

Jaschhof M. 1998. Revision der "Lestremiinae" (Diptera, Cecidomyiidae) der Holarktis. Studia Dipterologica Supplement 4: 1-552.

Jaschhof M. 2015. A review of the Aprionus flavidus group, with description of two new species close to Aprionus betulae Jaschhof (Diptera: Cecidomyiidae, Micromyinae). Studia Dipterologica 21: 221-229.

Jaschhof M. 2016. Taxonomic revision of some Micromyinae (Diptera: Cecidomyiidae) described by Zoya L. Berest. Zootaxa 4097: 255-262. https://doi.org/10.11646/zootaxa.4097.2.7

Jaschhof M. \& Jaschhof C. 2009. The Wood Midges (Diptera: Cecidomyiidae: Lestremiinae) of Fennoscandia and Denmark. Studia Dipterologica Supplement 18: 1-333. 
Jaschhof M. \& Jaschhof C. 2015. New species and new distribution records of Lestremiinae, Micromyinae and Porricondylinae (Diptera: Cecidomyiidae) in Sweden. Zootaxa 3973: 159-174. https://doi.org/10.11646/zootaxa.3973.1.6

Jaschhof M. \& Jaschhof C. 2017. Mycophagous gall midges (Diptera, Cecidomyiidae: Lestremiinae, Micromyinae, Winnertziinae, Porricondylinae): first records in Sweden and descriptions of closely related new species from elsewhere. Zootaxa 4226: 546-570. https://doi.org/10.11646/zootaxa.4226.4.6

Spungis V. \& Jaschhof M. 2000. Gall midges of subfamily Lestremiinae from Estonia, Latvia and Lithuania: checklist and description of new species (Diptera: Cecidomyiidae). Beiträge zur Entomologie 50: $283-316$.

Manuscript received: 28 November 2016

Manuscript accepted: 15 March 2017

Published on: 12 December 2017

Topic editor: Gavin Broad

Desk editor: Kristiaan Hoedemakers

Printed versions of all papers are also deposited in the libraries of the institutes that are members of the EJT consortium: Muséum national d'Histoire naturelle, Paris, France; Botanic Garden Meise, Belgium; Royal Museum for Central Africa, Tervuren, Belgium; Natural History Museum, London, United Kingdom; Royal Belgian Institute of Natural Sciences, Brussels, Belgium; Natural History Museum of Denmark, Copenhagen, Denmark; Naturalis Biodiversity Center, Leiden, the Netherlands; Museo Nacional de Ciencias Naturales-CSIC, Madrid, Spain; Real Jardín Botánico de Madrid CSIC, Spain. 